\title{
Estructura demográfica de Veragua en el siglo XVIII (I)
}

\author{
M. ${ }^{a}$ del Carmen Mena García \\ Departamento de Historia de América \\ Universidad de Sevilla
}

El censo de la provincia de Veragua, de 1756, mandado hacer por el gobernador, don Santiago Matías Gutiérrez, en cumplimiento de los reales decretos de 1741 y 175I, constituye una fuente de primer orden para el esclarecimiento de la demografía histórica de la provincia de Veragua que junto con las del Darién, Panamá y Portobelo, integraban en la segunda mitad del siglo XVIII la Gobernación y Comandancia General de Panamá.

En base a este extenso y completísimo documento, hasta ahora inédito, la autora analiza las características (estructura familias, composición étnica, distribución campo/ciudad, población esclava, etc.) de la población veragüense en el siglo XVIII.

\section{Precedentes}

De suma importancia para el conocimiento de la sociedad hispanoamericana en la época colonial resulta, sin dudas, el del potencial humano que la integró, su magnitud, composición y evolución a lo largo del tiempo. Tal aserto no constituye nada nuevo ni original. Desde tiempo inmemorial, todas las administraciones estatales se afanaron por averiguar los recursos materiales y humanos con los que contaban, con vistas a un mayor control y aprovechamiento de los mismos. Y la España que se proyectó al otro lado del Atlántico no iba a escapar a esta tónica general, antes por el contrario, dado su continuo carácter expansivo y sus móviles evangelizadores, se esforzó más que ningún otro estado por conocer la realidad de sus posesiones, especialmente la referida a sus recursos humanos, no sólo por un interés económico más que razonable, sino también para ejercer una estrecha vigilancia religiosa y cultural sobre los mismos. Con acierto, se ha reconocido que "pocos pueblos conquistadores tuvieron más claro que los españoles el aserto de que 
para establecer una perfecta relación de dominio sobre una sociedad es necesario previamente conocerla en profundidad". '

Ya en la segunda mitad del siglo XVI, la corona española, en su afán de sistematizar la voluminosa información que hacía llegar desde sus territorios de Ultramar, encomendó a dos eficientes funcionarios, Juan de Ovando y Juan López de Velasco, la redacción de una obra, concluida en 1574, gracias al definitivo impulso de éste último. La Geografía y Descripción Universal de las Indias, de López de Velasco, recogía ya 9.000 pueblos de naturales y unos 200 pueblos de españoles. Tan magno esfuerzo constituía, además, el primer cuerpo descriptivo, geográfico, económico y humano del que pudo disponer la corona para la administración colonial. Como es sabido, poco tiempo después, el Consejo de Indias, máximo organismo rector de los asuntos de Ultramar, volvió a recabar este tipo de descripciones que debían ser elaboradas in situ por las autoridades americanas mediante completísimos cuestionarios y que dieron lugar a lo que se conoce como Relaciones Geográficas, reunidas entre los años de 1575 a 1585 . Desde entonces hasta la cuarta década del siglo XVIII se sucedieron, con mayor o menor fortuna, diversos intentos oficiales para lograr un cuerpo documental de noticias, lo suficientemente amplio como para que abarcase toda la realidad indiana, entre los cuales pueden citarse el Compendio y Descripción de las Indias Occidentales, obra del fraile Antonio Vázquez de Espinosa, quien recorrió entre 1610 y 1622 el Nuevo Mundo y redactó su obra seis años después, o las tentativas de 1679 y 1681 , de similares características. ${ }^{2}$

Conforme transcurría el tiempo se hacía más urgente para el Consejo y las Secretarías de Indias disponer de informaciones exac-

I Arretx, Carmen; Mellafe, Rolando y Jorge L. Somoza: Demografía histórica en América Latina: Fuentes y Métodos. San José de Costa Rica, 1983, pág. 3.

2 Una información más amplia puede encontrar el lector, entre otras, en las siguientes obras: Sánchez Albornoz, Nicolás: La población de América Latina. Desde los tiempos precolombinos hasta el año 2.000. Madrid, 1977, en especial págs. 24 y ss. Arretx, Carmen y otros: Demografía histórica... Konetzke, Richard: Fuentes para la historia demográfica de Hispanoamérica durante la época colonial, "Anuario de Estudios Americanos", T. V, SeviIla, 1948, págs. 267-323. Woodrow, Borah: La demografía histórica de la América Latina: Fuentes, técnicas, controversias, resultados, "Cuadernos de Historia Social y Económica", n. ${ }^{\circ}$, Bogotá, 1972. 
tas y actualizadas que completasen el puzzle americano en su totalidad. Sobre todo ahora que la nueva política económica del Estado español hacía cada vez más necesaria la obtención de estos datos para un mejor control y dominio de sus colonias. Se ha dicho incluso que en el siglo XVIII España redescubre América: "se comienza a caer en la cuenta de que los distintos territorios que componían el imperio, tanto en España como en Indias, no formaban una unidad geográfica perfecta, sino que planteaban distintos problemas, ofrecían distintas características y posibilidades y reclamaban, por tanto, no una ley general, sino una serie de medidas particulares de fomento y desarrollo, para cuya adopción debía tenerse en cuenta la realidad geográfica". ${ }^{3}$ Un desgraciado suceso - el incendio del Palacio Real de Madrid - acaecido en 1734, vino a complicar aún más este panorama, ya que en el mismo se quemaron muchas de las descripciones y relaciones que se guardaban en este magno edificio.

Posiblemente para compensar esta lamentable pérdida, y, desde luego, para actualizar los informes existentes, el gobierno metropolitano decidió, por fin, cursar a las autoridades americanas una real cédula, el 19 de julio de 1741 , en la que se disponía que remitiesen relaciones detalladas sobre sus respectivos territorios para la confección de una nueva descripción general de las Indias. ${ }^{4}$ Una orden que, como a continuación veremos, habría de marcar un hito importante en el panorama de la demografía histórica de Hispanoamérica.

El virrey de la Nueva España, conde de Fuenclara, respondió diligentemente a lo dispuesto. Con el material recopilado, José An-

3 Muñoz Pérez, José: Papel de la geografía en el programa de reajuste económico del XVIII español. "Estudios geográficos", mayo-agosto, 1957, págs. 405 y 406. Citado por Serrera Contreras, Ramón M.": Estudio preliminar al Suplemento al Teatro Americano de José Antonio Villaseñor y Sánchez. México, 1980, pág. 46.

4 El preámbulo de lá citada orden la justificaba en que: "había acreditado la experiencia los graves inconvenientes y perjuicios que resultan de faltar en mi Consejo de las Indias las noticias más individuales y distintas del verdadero estado de aquellas provincias". En consecuencia, las autoridades indianas debían recabar de los alcaldes mayores y justicias de los partidos "las noticias particulares que necesiten para el conocimiento cierto de los nombres, número y calidad de los pueblos de su jurisdicción, y de sus vecindarios, de sus naturales, del estado y progresos de las misiones, de las conversiones vivas y de las nuevas reducciones". Konetzke, R.: Fuentess para la historia demográfica..., pág. 52. 
tonio de Villaseñor y Sánchez compuso su Teatro Americano. Descripción general de los reinos y provincias de la Nueva España, que fue impreso en México en 1748. Pero en lo que respecta a los virreinatos de Nueva Granada y Perú, no se actuó con la misma diligencia. Razón por la cual, en 1751, transcurridos ya diez años, se volvió a insistir por parte de la corona ante las autoridades de ambas jurisdicciones, Solís y conde de Superunda, quienes procedieron, por fin, a ejecutar lo dispuesto. Los resultados del distrito peruano fueron divulgados, por Cosme y Bartolomé Bueno en la Descripción del Virreinato del Perú, impreso en Lima entre 1763 y 1774.

Merced a estas iniciativas, que habrán de culminar en la ambiciosa empresa del censo general ejecutado en toda la América española por orden del ministro José de Gálvez (1776), se considera que es posible ya, a mediados del siglo XVIII, realizar una estimación documentada de la población de Hispanoamérica. ${ }^{5}$ De hecho, al promediar la centuria no hay casi ninguna provincia, ciudad o intendencia que no disponga de uno o varios recuentos de población a los que inapropiadamente se les ha llamado censos, a pesar de que muy pocos cumplen los requisitos necesarios para ser considerados como tales, siendo más bien descripciones geográficas que incluyen padrones de pobladores, registros de visitas pastorales, recuentos fiscales, militares, o con otros propósitos administrativos. Algunos de ellos, sin embargo, fueron realizados bajo la supervisión de visitadores, cabildos u obispos teniendo presente "una nueva forma de estadística demográfica". ${ }^{6}$

Hoy día todos los especialistas están de acuerdo en afirmar que no es posible hablar de un periodo propiamente estadístico de recolección de datos poblacionales sino hasta muy avanzado el si-

5 Sánchez. Albornoz, La población de América Latina..., pág. 28.

6 Arretx, Carmen y otros: Demografía en América Latina, pág. 23. Entre los especialistas que así lo denominan, citemos por ejemplo a W. Borah, quien en su obra La demografía histórica de la América Latina, pág. 37, dice así: "Una categoría especial de recuento, el censo, que ofrecía información sobre cifras totales, sexo, edad, raza y ocupación y todo lo que quisiera preguntar la autoridad central, apareció a mediados del siglo XVIII. Una serie de experimentos realizados por medio de las autoridades civiles y religiosas que ensayaban diferentes clases de información deseada por motivos administrativos perfeccionó lentamente la técnica a lo largo de más de medio siglo". 
glo XIX. Sánchez Albornoz, por citar uno de ellos, considera que la etapa estadística se inicia en 1880 , momento a partir del cual el relevamiento de los datos de población corre a cargo exclusivo del Estado que los efectúa de una manera sistemática, tanto en las técnicas de elaboración primaria, como en la forma de presentarlos. ${ }^{7}$ Pero del mismo modo, existe la opinión generalizada de que, en conjunto, todos los censos o recuentos de población, elaborados a mediados del siglo XVIII, ya sean parciales o totales, pueden ofrecer una información valiosísima siempre que se les someta a un análisis riguroso.

\section{El padrón de la provincia de Veragua de 1756}

Un censo o recuento parcial que hasta la fecha continua inédito es el de la provincia de Veragua, de 1756, que descubrimos hace ya bastante tiempo cuando investigábamos en los fondos del Archivo General de Indias (AGI), en concreto, en la Sección Audiencia de Panamá, legajo 130. No en razón de su interés, que es mucho, como podrá comprobarse, sino de las dificultades que presuponíamos para su edición, ya que se trata de un documento bastante extenso, fuimos postergando la idea de su publicación quizá por demasiado tiempo. ${ }^{8}$

El documento objeto de nuestro estudio se denomina Padrón general de toda la provincia de Veragua en sus términos y gobernaciones que se ha hecho, por orden de Su Majestad, por don Santiago Matías Gutiérrez, gobernador actual de ella. Año de 1756. En él se recojen todos los pobladores de la provincia de Veragua, que junto con las del Darién, Panamá y Portobelo, integraban en la se-

7 Sánchez Albornoz, La población de América Latina..., pág. 28.

8 Por gentileza de la revista "Anuario de Estudios Americanos" podemos publicar este magnífico recuento que no dudamos interesará al lector. Nuestro agradecimiento, por ello, a la citada revista. Por otro lado, conviene matizar aquí que una pequeña parte de nuestro censo, concretamente la relativa a la ermita de David, fue publicada por Alberto Osorio en su obra: Historia de la Ciudad de David, Panamá, 1974. También del citado autor son: Santiago de Veragua Colonial, Panamá, 1989 y Chiriquí en su Historia (1502-1903), Panamá, 1986. 
gunda mitad del siglo XVIII, la Gobernacion y Comandancia general de Panamá. ${ }^{9}$

¿Qué sabemos al respecto? Resulta claro que el empadronamiento fue mandado hacer por el gobernador de Veragua D. Santiago Matías en cumplimiento a lo dispuesto por los decretos de 1741 y 1751, ya mencionados. ${ }^{10}$ Pero, ¿cuál fue el criterio o los criterios del empadronamiento? y ¿quiénes fueron los encargados de su realización?. La documentación consultada alude a que en su realización participaron los "ministros de cabezas de partido". ¿Pero quizás no tuvieron que ver en ello, especialmente en los pueblos de indios, también una parte del clero que tan de cerca vigilaba a sus neófitos? ¿Cómo saber el verdadero alcance de las clasificaciones raciales? ¿Se atuvieron los empadronadores a un criterio biológico o prevaleció más bien la situación económica para blanquear la piel y ocultar la verdadera condición étnica de los censados? ¿Qué márgenes de error esconde el documento? En una sociedad mestiza y rural, como fue la de la provincia de Veragua, con una población indígena recién asimilada, o todavía en pie de guerra, y con una frontera de límites imprecisos, es fácil imaginar que un cierto porcentaje de individuos, imposible de precisar, pudo escapar al recuen-

9 En 1751 se suprime la Audiencia de Panamá y pasa a convertirse en Gobernación y Comandancia General. En el siglo XVIII Panamá, que desde 1739 ha visto comoo se suprimía la famosa feria de Portobelo, sufre diversos cambios administrativos que no muestran más que su decadencia económica.

10 Entre la correspondencia del gobernador de Panamá, encontramos una carta dirigida a la Corona y fechada en 1754, en la que se hace alusión al decreto dado el 2 de septiembre de 1751 reiterando una orden anterior, de 19 de julio de 1741 , en la que se ordenaba a los virreyes del Perú y del Nuevo Reino de Granada, los presidentes de las Audiencias y los gobernadores de sus distritos que enviasen una relación detallada del estado de estos territorios. El gobernador panameño justificaba su tardanza en que: "por hallarme con orden del virrey de Santa Fe para que le comunique las noticias conducentes al conocimiento de este Reino, y aunque las tengo pedidas a los ministros de cabezas de partido, todavía no las he recibido de todas partes...". Una pequeña anotación, a espaldas de este escrito, (5, julio, 1755) testimoniaba el interés del Consejo por este asunto, ya que disponía textualmente "que se le de prisa al gobernador y que se le pida un mapa geográfico puntual y circunstancial de todo el Reino y provincia". El gobernador de Panamá a S. M. Panamá, 26 de octubre de 1754. AGI, Panamá, 130. Dada la coincidencia de las fechas, el Padrón de la provincia de Veragua, de 1756, formaba parte, sin duda, de la descripción general del Reino encargada por la Corona a sus posesiones ultramarinas en las fechas mencionadas. Lamentablemente no hemos podido localizar, como hubiera sido nuestro deseo, el mapa aludido. 
to. De hecho, constatamos frecuentes alusiones a pobladores "huidos" por razones que no se especifican.

Estas y otras muchas interrogantes, que iremos planteando a lo largo de nuestro estudio, nos hacen sospechar que estamos en presencia de un registro de altísima omisión que requiere, como tantos otros censos parciales y generales del siglo XVIII, de una labor previa de crítica y ajuste. Y dado que no pretendemos que este censo constituya una medición precisa, sino un orden de magnitud, no dúdamos de que servirá como un primer hito de referencia que contribuirá, en un futuro, al esclarecimiento de la demografía histórica de Hispanoamérica.

\section{Contenido y valoración del Padrón de Veragua}

A modo de presentación creemos conveniente hacer una breve referencia al conjunto de la información que nos proporciona el $\mathrm{Pa}$ drón de Veragua de 1756, que reproducimos en su totalidad en las páginas siguientes, modernizando la grafía y la puntuación, según el criterio establecido en la transcripción de documentos del siglo XVIII, para hacerlo más inteligible. De este modo el lector podrá calibrar, en su justa medida, tanto la prolijidad de los datos y la riqueza del documento como las lagunas o ausencias con las que tuvimos que enfrentarnos a la hora de realizar el análisis y cuantificación del mismo.

Dadas las características del documento, son los aspectos demográficos los que priman. Y como cualquier otro censo parcial del siglo XVIII podría esperarse de él la siguiente información:

1.- habitantes por parroquias, ordenados por sexos, grupos étnicos y castas.

2.- - edades de la población.

3. - estado civil.

4.- - grupos ocupacionales.

5.-población extranjera. 
Pero también existe un mínimo posible que se reduciría solamente a la anotación del número total de habitantes distribuidos por sexos y grupos étnicos.

El Padrón de Veragua ocupa un lugar intermedio entre los dos extremos que acabamos de señalar. En efecto, carece de algunos de los apuntes que mencionamos, pero abunda en interesantes referencias a muchos otros aspectos de indudable interés para el conocimiento de la sociedad veragüense y que no son usuales en los recuentos que se conocen para esta misma época.

Anotemos, en primer lugar, como dato curioso, el hecho de que cada una de las demarcaciones de la provincia, ya sea ciudad, sitio, ermita o pueblo de indios se acompaña y precede de una curiosa información urbanística en la que se recoje no sólo el número de viviendas sino también la morfología constructiva de las mismas: "casas de caña cubiertas de barro y techumbre de paja"; "bajas, de madera, cercadas de quincha y cubiertas de tejas", o en la modalidad de "casas de cañón" tan característica en la tipología de la vivienda panameña, con techos de tejas, de una o dos aguas, y elevación de una o dos alturas. Todo hace indicar que estamos en presencia de un paisaje rural en el que la pobreza constructiva es la nota predominante. Otras alusiones a la existencia de numerosas casas de alquiler y "en asesoría" (accesoría o prolongación de la vivienda principal) que predominan en Santiago de Veragua, capital de la provincia, hablan por sí solas de la necesidad de dar cobijo a una población flotante, "de forasteros" cuya demanda es, sin duda, aquí más destacada.

A continuación, en cada recuento se nos proporciona una información administrativo-judicial: relación de las autoridades de cada distrito, y eclesiástica: descripción de la iglesia y nombre de sus miembros.

El Padrón de Veragua emplea como pauta demográfica o unidad censal la familia. En este caso se trata de la familia extensa a la que se describe por el nombre y número de sus miembros. Sin embargo, se echa en falta una información más completa y detallada de la estructura étnica y del estado civil de sus miembros, pues aunque en ocasiones estos datos se hacen constar, no siempre se si- 
gue un mismo criterio, lo que sería deseable para lograr una mayor uniformidad en el registro, e imprescindible para cuantificar las cifras con un mínimo de rigor. Lo mismo podría decirse respecto al origen de los pobladores, pues sólo encontramos alusiones fragmentadas, tales como "natural de los Reinos de España", o "natural de la ciudad de Panamá". El Padrón no alude tampoco a las edades de la población que es censada y sólo en ocasiones figuran con ocupación determinada.

Por el contrario, hay otros datos de interés, no tan usuales en otros registros, que merecen destacarse y que permiten extraer interesantes conclusiones de la sociedad veragüense: en especial el número de esclavos que posee cada familia y el volumen de la cabaña ganadera de cada unidad administrativa.

Analicemos a continuación todos los aspectos mencionados con mayor detenimiento.

\section{a) Cifras totales}

En 1756 anotamos la existencia de 12.048 habitantes para toda la provincia de Veragua, según nuestros cálculos, y 12.081, según los totales que arroja el censo. Trabajaremos de aquí en adelante con nuestras cifras por cuanto en el citado documento aparecen evidentes errores de suma e incluso de parciales correspondientes a cada "unidad censal".

Padrón de Veragua Suma corregida

Santiago de Alanje y sus términos

Nuestra Señora de los Remedios

y sus términos

Santiago de Veragua y sus términos
2.556

2.567

801

8.724

12.081
798

8.683
12.048

TOTAL:

La relación completa de los lugares mencionados en nuestro censo la incluimos a continuación en el cuadro n..$^{\circ} 1$ para facilitar al lector la comprensión de los datos que aquí se exponen. 


\section{CUADRO N." 1}

PADRÓN DE LA PROVINCIA DE VERAGUA. AÑO 1756

100. SANTIAGO DE ALANJE. CIUDAD

110. Sitios

111. Sitio de Tijera y Chiriguagua

112. Sitio del hato de la iglesia y embarcadero

113. Sitio del Guarumal y Piedras Hincadas

114. Sitio de la Pita y Guabitos

115. Sitio del Tullido y Avacas

120. Ermita de David

121. Sitio de las Quebradas

122. Llano de David hasta el Mangote

123. Sitio de las Lomas

124. Sitio del Guayabal

125. Sitio de Cochea

126. Sitio de Dolega

127. Sitio de Chorcha

130. Pueblos

131. Pueblo de San Pablo

132. Pueblo de Boquerón

133. Pueblo de Bugaba

200. NUESTRA SEÑORA DE LOS REMEDIOS. CIUDAD

210. Pueblos

211. Pueblo de San Feliz

212. Pueblo de San Rafael

213. Pueblo de San Lorenzo 
300. SANTIAGO DE VERAGUA. CIUDAD

310. Sitios

311. Llano del Algarrobo

312. Sitio de Cañazas de Santa María

313. Cerro de Inés hasta la Galera

314. Sitio del Corral Falso y las Mesillas

315. Sitio de Martín Tozere y Hatillos

316. Sitio del Montijo

317. Sitio de la Trinidad y Ermita del Río Jesús

318. Sitio del Carrizal y Mojaraz

319. Sitio de Conaca, Peana y Galera

320. Sitio de la Peña hasta San Pedro y el Cacao

321. Sitio de Boba, Corita y Cañazas

322. Sitio de Ponuga y Potrero

330. Pueblos

331. Pueblo de San Marcelo de León, Mesa de Tabaraba

332. Pueblo de San Francisco de la Montaña

333. Pueblo de San Miguel de la Atalaya

334. Pueblo de San Francisco Javier de Cañazas

\section{b) Estructura familiar}

Como ya adelantamos, los datos poblacionales han sido recogidos por unidad familiar, lo que significa que es la familia la que constituye la unidad censal del documento. Al igual que en el censo de Jujuy, de 1778-1779, podemos afirmar con palabras de Ricardo Rojas que "los empadronadores han seguido un método excelente; el de agrupar familia por familia, dando a esta voz su latitud antigua, es decir, incluyendo en la casa de los paterfamilias, sus bastardos, sus siervos, sus criados, sus esclavos, su clientela económica y cuantos moraban bajo el mismo techo del señor. Por eso el censo 
apunta, a continuación de cada casa, la suma parcial de los individuos que la constituyen". "I

Se trata, por consiguiente, de un concepto especial de la familia a la que se denomina tambien como familia extensa o social y que se caracteriza por un grupo de personas que componen el núcleo - fundamentalmente padres e hijos - al que se añaden parientes, más o menos directos (se da, a veces, el caso de padres conviviendo con hijos casados con sus respectivas familias e hijos), esclavos y agregados que comparten una misma vivienda bajo la autoridad del jefe de familia. Junto con las formas familiares señaladas, observamos la existencia de un porcentaje bastante considerable de individuos aislados, ya sean viudos/as o célibes que hemos considerado, en nuestros cálculos como una unidad censal más, ya que ocupan por sí solos una vivienda y a todos los efectos deben ser considerados como tales. El porcentaje de estos individuos en la población total es de $5,95 \%$.

En general los promedios de miembros por familia van de 6,5 a 1,2 en los grupos familiares nucleares y desde 8 a 2,8 en las unidades censales (Véase cuadro n. ${ }^{\circ}$ 2). Siendo el promedio general para toda la provincia de 3,8 para el primero y de 4,6 para el segundo. Casi cuatro personas componían, por tanto, la familia-tipo en la provincia de Veragua con lo cual quedaba asegurado el reemplazo sosegado de las generaciones.

El cuadro n. ${ }^{\circ} 2$ nos permite reflejar las oscilaciones en el promedio de hijos por familia. Los cálculos se hicieron por unidades conyugales, incluyendo los matrimonios incompletos (viudos/as) y los célibes con hijos. A nivel provincial, la media de 2,3 no hace más que garantizar el mantenimiento del volumen de la población. Si exceptuamos los matrimonios sin hijos, la media se eleva a 3,3 y nos acerca mucho más a la realidad. No obstante, hay que tener presente que nuestros cálculos han sido elaborados exclusivamente sobre los hijos que en el momento de levantarse el censo vivían con

11 Citado por Beatriz Rasini: Estructura demográfica de Jujuy. Siglo XVIII, en América Colonial. Población y economía, pág. 120. Elda R. González y Rolando Mellafe tratan más ampliamente esta cuestión en: La función de la familia en la Historia Social de Hispanoamérica. Ibídem, págs. 57-71. 
sus padres y no con aquellos que ya se habían separado del núcleo paterno o con los nietos que convivían - sin sus padres- con los abuelos. Del mismo modo, nos hemos visto obligados a excluir los pueblos de indios de Boquerón, Bugaba, San Feliz y San Rafael, dado que en estos casos los datos poblacionales no siguen la pauta de unidad censal - familia por familia - que se utiliza en el resto del recuento.

Las numerosas alusiones a hijos "entenados" o hijastros, que recoge el censo, hace pensar en la inestabilidad matrimonial y en el establecimiento de nuevos vínculos con relativa frecuencia, algo que desde luego no sorprende, si se tiene en cuenta que las condiciones sanitarias eran aún muy deficientes y la expectativa de vida muy limitada. La viudedad, fue un hecho muy frecuente, pero no el único responsable de este fenómeno. A nuestro parecer, debe tenerse también en cuenta el porcentaje de mujeres solteras con hijos que en determinado momento decidieron buscar en el matrimonio la estabilidad de la que carecían. Sin embargo, queda por confirmar esta apreciación, puesto que el censo si bien registra a los casados, como tales, no siempre especifica la soltería o viudedad.

Como ya adelantamos en páginas anteriores, hemos operado por exclusión, considerando como soltero/a a todo aquel que no se especifica, pero la duda se plantea especialmente en el caso de los varones. ¿Cúantos de los varones que figuran en el registro sin pareja y con hijos no pudieron ser más bien viudos, en lugar de solteros? E incluso cabría plantearse una segunda interrogante: ¿cúantos de los hombres y mujeres solteros o sin identificar su estado civil no formaban parte, más bien, de parejas y familias recién constituidas que nunca legalizaron su unión en las parroquias? Es bien sabido que la sociedad mestiza y rural de Iberoamérica mostró siempre una alta tendencia a las uniones libres, ilegítimas, sin sanción religiosa alguna de las parejas, más que la que le proporcionaba el grupo o comunidad donde se establecían. La incógnita queda por despejar. Conscientes de que se trata de un registro de escasa fiabilidad, hemos renunciado a ponderar los porcentajes correspondientes.

El estado civil de los veragüenses sólo aparece consignado, sin ninguna duda, en el caso del pueblo de indios de San Francisco de 
la Montaña, perteneciente al distrito de la ciudad de Santiago de Veragua. Viudos y viudas se agrupan al final del recuento, lo cual no deja ninguna duda al hecho de que el resto, en el caso de que no se señale, son solteros/as. Aquí el porcentaje de casados es del $77 \%$, seguidos de un $13 \%$ de viudos ( $9 \%$ de viudas y $4 \%$ de viudos) y más de un $9 \%$ de solteros ( $8 \%$ de solteros y $1,2 \%$ de solteras). Un dato a destacar es el referido al elevado número de solteras con hijos que figuran en el censo. El $81 \%$ de las solteras mantiene una prole, en ocasiones numerosa, lo que hace pensar en una sociedad con un grado de relajación moral importante.

Por último, en lo que respecta a la clasificación por sexo, sólo podemos ponderar aquellas cifras recogidas para los cabezas de familia, puesto que en el caso de los hijos, agregados o esclavos este aspecto se silencia. El porcentaje hombre/mujer para los cabezas de familia recogidos en cada unidad censal es de un total de 3773 personas, el $46 \%$ de varones y el $53 \%$ de mujeres. ${ }^{12}$

CUADRO N. ${ }^{\circ} 2$

ESTRUCTURA FAMILIAR

Distrito Familias Fam. nuclear Hijos/Fam. Fam. extensa

\begin{tabular}{lrlll}
\hline 100 & 45 & 3.3 & 1.7 & 5.5 \\
111 & 39 & 4.2 & 2.4 & 6.5 \\
112 & 40 & 4.2 & 2.6 & 5.6 \\
113 & 22 & 5.4 & 3.6 & 6.0 \\
114 & 68 & 4.3 & 2.5 & 5.4 \\
115 & 15 & 3.6 & 2.0 & 4.7 \\
120 & 73 & 4.3 & 2.6 & 6.5 \\
121 & 3 & 6.3 & 4.3 & 7.6 \\
122 & 13 & 4.6 & 2.7 & 6.3
\end{tabular}

12 También aquí exceptuamos los pueblos de indios de Boquerón, Bugaba, San Feliz y San Rafael por carecer de estos datos. 
CUADRO N.․ 2 (continuación)

Distrito Familias Fam. nuclear Hijos/Fam. Fam. extensa

\begin{tabular}{rrrrr}
\hline 123 & 16 & 3.6 & 1.7 & 4.6 \\
124 & 2 & 6.5 & 5.0 & 7.0 \\
125 & 5 & 6.0 & 4.2 & 8.0 \\
126 & 4 & 4.2 & 2.2 & 6.0 \\
127 & 42 & 4.7 & 2.8 & 5.8 \\
131 & 19 & 3.5 & 0.8 & 3.5 \\
132 & 83 & 1.9 & - & - \\
133 & 43 & 1.2 & - & - \\
200 & 149 & 2.9 & 1.4 & 2.9 \\
211 & 65 & 1.8 & - & - \\
212 & 72 & 1.7 & - & - \\
213 & 39 & 2.5 & - & - \\
300 & 195 & 4.0 & 2.4 & 6.7 \\
311 & 19 & 4.2 & 2.7 & 5.0 \\
312 & 17 & 3.1 & 1.4 & 3.5 \\
313 & 22 & 5.0 & 3.3 & 6.1 \\
314 & 29 & 4.4 & 2.7 & 5.3 \\
315 & 78 & 4.5 & 2.7 & 4.6 \\
316 & 107 & 4.7 & 3.0 & 4.7 \\
317 & 110 & 4.6 & 2.8 & 4.7 \\
318 & 19 & 5.8 & 4.0 & 7.1 \\
319 & 50 & 4.1 & 2.4 & 5.1 \\
320 & 104 & 5.5 & 3.8 & 6.4 \\
321 & 70 & 5.1 & 3.4 & 5.5 \\
322 & 163 & 4.9 & 3.2 & 5.6 \\
331 & 328 & 4.7 & 3.0 & 5.2 \\
332 & 244 & 3.9 & 2.0 & 4.3 \\
333 & 45 & 5.0 & 3.5 & 5.3 \\
334 & 34 & 3.5 & 1.5 & 3.6 \\
TOTAL: & 2.491 & 3.8 & 2.3 & 4.6
\end{tabular}




\section{c) Composición étnica}

Pese a que la documentación censal preestadística del siglo XVIII muestra, en general, una importante preocupación racial, no ocurre así en nuestro caso.

Ya hablamos en páginas anteriores de la dificultad de cuantificar la composición racial de los pobladores de Veragua, especialmente por razones metodológicas. Es imposible establecer generalizaciones cuando este dato no es recogido con uniformidad. En diferente forma se precisa la filiación étnica en los distritos que integran la provincia. En la ciudad de Nuestra Señora de los Remedios, por ejemplo, se menciona la casta como encabezamiento de cada grupo. Así después de los criollos blancos, blancos de estas Indias, siguen mestizos y mulatos, y zambos y negros, haciéndose anotar, al final de recuento, a las viudas y solteras de las distintas etnias. Y lo mismo ocurre en el pueblo de San Lorenzo, jurisdicción de la ciudad mencionada, en donde con el mismo criterio, se registran indios, mestizos, y zambos.

Por el contrario, en el resto de los distritos no aparecen encabezamientos globales, como los señalados, sino sólo menciones aisladas sobre la condición racial de algunos pobladores, o en el mejor de los casos, generalizaciones como vecinos españoles y de color, de escasa utilidad a la hora de establecer conclusiones.

Un caso excepcional es el de la población india: "indios de armas", "tributarios", o "agregados" a los que se presta una especial atención en el recuento, dado que por estos años se vive en la gobernación un importante proceso de integración cultural de amplias franjas marginales, de reductos indígenas hasta ahora no asimilados y que constituyen una preocupación de primer orden para las autoridades. La destacada labor misional de la Iglesia servirá para incorporar a la llamada población infiel - generalmente indígenas que vivían en pie de guerra o que estaban en proceso de evangelización - a la civilización facilitando no sólo su aculturación y adoctrinamiento, sino también el control de sus territorios. 
En efecto, a lo largo del siglo XVIII la numerosa población guaymí que habitaba dispersa a lo largo de la Cordillera Central, en las montañas de Veragua y Chiriquí, será lentamente atraida a las sabanas del Pacífico afianzando una red de poblamiento, de unos 200 kilómetros, desde el monte Tute en Veragua hasta los confines de Chiriquí en su frontera con Costa Rica, que pese a verse amenazada en repetidas ocasiones por los ataques y revueltas de los indios o por la torpeza de los misioneros, vigorizó un territorio que hasta entonces se había caracterizado por la debilidad de sus estructuras económicas y por la escasez de hombres. ${ }^{13}$

Las cifras hablan por sí solas del éxito obtenido por la Iglesia católica en esta empresa: de 1736 a $1789^{14}$ el número de doctrinas de indios crece de 6 a 15 . Y este incremento se acompaña de un crecimiento paralelo del número de aborígenes integrados en la cultura y en el espacio colonial: 2.262 indios son censados en 1736, 3.325 en 1756 y 7.762 en 1787 .

Para 1756, fecha en la que se realiza el Padrón de Veragua, el porcentaje de indios integrados o "ladinizados" alcanza ya un valor significativo del $27,6 \%$ sobre el total de la población veragüense.

En la seguridad de que la convivencia hispano-indígena redundaría en beneficio de la población aborigen recién asentada, la Iglesia fomentó la instalación de familias españolas y mestizas en las doctrinas de indios. En efecto, otros documentos consultados nos muestran cómo, a instancias de los misioneros, las autoridades civiles de Panamá dieron toda clase de facilidades a los colonos españoles que voluntariamente aceptaron marchar a los nuevos pueblos de indios y les aseguraron los medios para su subsistencia. En 1756, por ejemplo, una carta del obispo de Panamá solicitaba la licencia del gobernador para que según "la introducida costumbre", pudie-

13 Jaen Suárě. Omar: La población del istmo de Panamá. Panamá, 1979, pág. 74.

14 Relación Geográfica del Obispo de Panamá fray Pedro Morcillo y Auñón (1736). Publicada por Gasteazoro, Carlos Manuel: Introducción al estudio de la Historia de Panamá. Fuentes de la época hispana. 2a edición, Panamá, 1990. Silvestre, Francisco: Descripción del Reino de Santa Fe de Bogotá (1789). Publicada por J.A. Susto, Panamá, 1927. 
sen residir en el, recién fundado, pueblo de indios de San Francisco Javier de Cañazas, en la jurisdicción de Santiago, provincia de Veragua, 12 familias de españoles y gentes de color. Se consideraba que la cohabitación de los indios con españoles y mestizos facilitaría el proceso de aculturación y evangelización de los primeros y al mismo tiempo aseguraría su sometimiento: "porque la residencia de españoles sirve de freno en los casos que suelen amotinarse los indios como porque la comunicación con ellos les es maestra para los actos de religión y buenas costumbres y para la más fácil erudición de la lengua española y veneración a la Divina Majestad que se le permite tener sacramentada en su iglesia". ${ }^{15}$

Por estas fechas otros pueblos de indios de la provincia de Veragua mostraban esta misma tendencia. Así el pueblo de San Lorenzo, en el distrito de Nuestra Señora de los Remedios, con 110 habitantes, se componía de 43 mestizos, 13 zambos y 54 indios, es decir, apenas el 50\% eran naturales. El pueblo de San Marcelo de León, perteneciente al distrito de Santiago de Veragua, capital de la provincia, contaba con 146 vecinos españoles y de color que residían en 23 casas y 1617 naturales en 338 casas, con lo que el porcentaje del $8 \%$ de españoles y mestizos, aún siendo más reducido que en el caso anterior, representaba un aporte significativo. Lo mismo puede decirse del pueblo de San Francisco de la Montaña en donde convivían 236 vecinos españoles y de color, en 38 casas, y 830 indios en 208 casas. Aquí la presencia de españoles y mestizos aumentaba hasta el $22 \%$.

15 AGI, Panamá, 130. El obispo de Panamá al gobernador. Panamá, 1 de diciembre de 1756. Como hemos podido comprobar, en realidad no fueron 12 sino 66 las familias que acudieron a Cañazas, según se desprende del padrón efectuado en el citado pueblo en 1755, es decir, un año antes de que el gobernador otorgara su permiso. Lo cual parece demostrar que el traslado se había efectuado antes de que la sanción oficial fuera concedida y desde luego por un número muy superior al previsto. "Padrón de los vecinos de Cañazas que no son indios, hecho este año de 1755 en: Testimonios de autos sobre la población del pueblo de San Francisco Javier de Cañazas y reducción de los indios guaymies sujetos a esta doctrina en la jurisdicción de Santiago de Veragua, provincia del Reino de Tierra Firme". AGI, Panamá, 130. También es preciso aclarar aquí que el Padrón de la provincia de Veragua, de 1756, que analizamos en este estudio recoje sólo una población de 105 indios, más 16 españoles, entre autoridades y religiosos, seguramente porque el registro de los pobladores de Cañazas se efectuaría con anterioridad a la fecha en la que el padrón fue completado. 


\section{d) Población urbana y rural}

Un factor indispensable a averiguar es la delimitación entre lo urbano y lo rural y el tipo de asentamiento que determina pero, al mismo tiempo, existe una enorme dificultad para distinguir ambas variantes. En primer lugar porque habría que esclarecer cuál fue el criterio de la época a la hora de dividir a la población que vive en el "campo" y en la "ciudad". Parece evidente, además, que si aplicamos nuestra concepción de lo "urbano" muy pocas ciudades de la época colonial podrían considerarse como tales.

Para la centuria que nos ocupa, al margen de la diferenciación ecológica entre urbano y rural que se manifiesta en infraestructuras de distinta índole, es preciso tener en cuenta otros elementos, como las variaciones en la estructura y en las relaciones sociales, en las relaciones de producción y en la forma en que se manifiesta el poder. Sin embargo, lo normal es que los censos de la etapa pre-estadística carezcan de una orientación definida respecto a la consideración urbana o rural de la población censada, siendo necesariamente el investigador quien tenga que elaborar sus propios criterios. ${ }^{16}$

Las proporciones que nos muestra el padrón de Veragua, a falta de otros estudios con los que poder contrastar y precisar nuestra afirmación, son las de una población eminentemente rural. Los habitantes de la provincia de Veragua muestran una marcada preferencia por residir con sus familias en la campiña. El caso más llamativo es el de Santiago de Alanje. Aquí habitan sólo 249 vecinos en 45 casas; el resto, hasta 2.567 (90\%), que es el total de su población, vive "en los campos". La ciudad de Santiago de Veragua, capital de la provincia, tiene sólo 1.315 vecinos en 204 casas, de un total de 8.683 habitantes que registra todo el distrito, lo que indica un porcentaje de $85 \%$ en el campo, frente al $15 \%$ en la ciudad. Una distribución campo/ciudad más equilibrada encontramos en Nuestra Señora de los Remedios. Aquí las diferencias se acortan, ya que la ciudad cuenta con 443 vecinos en 150 casas (55.5\%), mientras que en el campo residen tan sólo 355 (44.5\%).

16 Arretx, Carmen y otros: Demografía histórica en América Latina, pág. 15. 


\section{e) La propiedad de esclavos como indicador socioeconómico}

No es este el lugar adecuado para analizar la importancia que tuvo la esclavitud en la economía de la provincia panameña de Veragua. Solamente señalaremos la disponibilidad de esclavos de las élites. Esta relación nos indica en cierta manera el poder económico de un sector de la sociedad de Veragua en razón de que la inversión en la compra de esclavos - aunque su valor oscilaba según la edad, el sexo, las condiciones físicas y aptitudes - era relativamente alta. En consecuencia, la propiedad de esclavos es un indicador del status económico que no debemos pasar por alto en nuestro estudio.

Hemos computado un total de 604 esclavos (5\% del conjunto de la población de Veragua) para toda la gobernación que se distribuyen en la siguiente proporción:

Esclavos Amos Promedio

\begin{tabular}{lcccc}
\hline $\begin{array}{l}\text { Distrito de Santiago de Alanje } \\
\text { Distrito de Nuestra Señora } \\
\text { de los Remedios }\end{array}$ & 208 & 61 & 3.4 \\
$\begin{array}{l}\text { Distrito de Santiago de Veragua } \\
\text { TOTAL: }\end{array}$ & 396 & - & 96 & - \\
\hline
\end{tabular}

El promedio de esclavos en toda la gobernación es de cerca de 4 por familia (dueña de esclavos). Pero este porcentaje registra oscilaciones que merecen ser consideradas. En Santiago de Alanje, la zona rural muestra una mayor concentración de esclavos que en la ciudad cabecera del distrito: 168 esclavos en contra de 40 en la urbe; 3,7 esclavos por amo en el campo y 2,5 en la ciudad. La ermita de David tiene por sí sola 58 esclavos frente a los 40 esclavos que trabajan en la ciudad de Alanje. Los propietarios de esclavos en los campos de David disponen de una media de 5,3 esclavos. Pero esta 
tendencia se nos muestra inversa en el caso de Santiago de Veragua y su campiña. Aquí, por el contrario, es la ciudad la que muestra una mayor disponibilidad de mano de obra esclava: 303 esclavos frente a 93 en la zona rural; 4,6 esclavos por amo en la ciudad frente a 3,0 en el campo. Se constata, por tanto, que el porcentaje de los jefes de familia que posen esclavos, es decir, los más ricos, que habían renunciado a su morada urbana para instalarse en el campo, es mucho más alto en el distrito de Santiago de Alanje que en el de Veragua.

De los 157 amos que aparecen censados en la gobernación de Veragua en 1756 no hay uno solo que no reciba el tratamiento de "Don". Pertenecen por derecho propio a la élite veragüense y se concentran en la capital de la gobernación: Santiago de Veragua. Aquí residen 65 amos que acaparan el $50 \%$ del total de esclavos de la provincia. No en vano son ellos los que disfrutan de un número más elevado de esclavos. En Santiago algunos propietarios cuentan con 16, 20 e incluso 32 esclavos, cifra récord. De los 96 amos que anotamos en el censo para el distrito de Santiago de Veragua, 9 de ellos poseen más de 10 esclavos, mientras que en Santiago de Alanje sólo aparece registrado uno con 18 esclavos.

Sin embargo, las elevadas cifras que comprobamos en lo que respecta a la sede capitalina se diluyen en el total provincial. En conjunto, los amos de la provincia de Veragua disponen en su mayoría de uno o dos esclavos (52\%); de 3 a 5 esclavos el $19 \%$; de 5 a 10 el $23 \%$ y más de 10 esclavos el $6 \%$.

Nuestra Señora de los Remedios y su pequeño distrito rural formado por los tres pueblos de indios de San Feliz, San Rafael y San Lorenzo carecía de mano de obra esclava. Probablemente sea éste uno más de los indicadores que muestran cómo la antigua capital de la provincia de Veragua (al menos hasta 1650) y una de las más importantes arterias de comunicación marítima con Panamá hasta entonces, no había conseguido recuperarse del colapso económico experimentado un siglo atrás. ${ }^{17}$

17 Castillero Calvo, Alfredo: Estructuras sociales y económicas de Veragua desde sus origenes históricos. siglos XVI y XVII, Panamá, 1967.

Tomo L. num. 2, 199.3 


\section{f) La cabaña ganadera de Veragua a mediados del siglo XVIII}

Mientras el avance de la colonización rural va perfilando lenta pero significativamente las sabanas de Veragua, crecen y se desarrollan en los nuevos espacios incorporados los hatos ganaderos favorecidos por un ecosistema que proporciona pastos naturales en abundancia. El triunfo de la ganadería extensiva parece evidente ya a mediados del siglo XVIII en una sociedad campesina, como la veragüense, que ha sido desde los inicios de la época colonial más que de labradores, tributaría de la cría ganadera.

En 1756 el volumen de la cabaña ganadera de la provincia de Veragua asciende a 84.728 reses. Pero es preciso tener cuidado con esta cifra por cuanto en el recuento que analizamos se omiten los totales correspondientes a los pueblos de indios de San Miguel de la Atalaya y San Francisco Javier de Cañazas. En éste último se hace constar que "no se ha podido averiguar su número por tenerlos (los indios) en las montañas". En consecuencia, no parece muy acertado utilizar el total de reses mencionado en el padrón para contrastarlo con el existente en otros periodos históricos, como en alguna ocasión se ha hecho, ya que se trata de un registro de altísima omisión.

GANADO VACUNO DE LA PROVINCIA DE VERAGUA. AÑO DE 1756

Población

$n .{ }^{\circ}$ de reses

Santiago de Alanje y distrito

Nuestra Señora de los Remedios y distrito

Santiago de Veragua y "sitios"

a) Pueblo de San Marcelo de León

b) Pueblo de San Francisco de la Montaña

c) Pueblo de San Miguel de la Atalaya

d) Pueblo de San Francisco Javier de Cañazas

$\left.{ }^{*}\right)$ en blanco el espacio correspondiente.

$\left({ }^{* *}\right)$ Se hace constar: "no se ha podido averiguar su número por tenerlo en las montañas". 


\section{GRÁFICO № 1 \\ DISTRIBUCIÓN GENERAL DE LA POBLACIÓN \\ DE VERAGUA EN 1756}

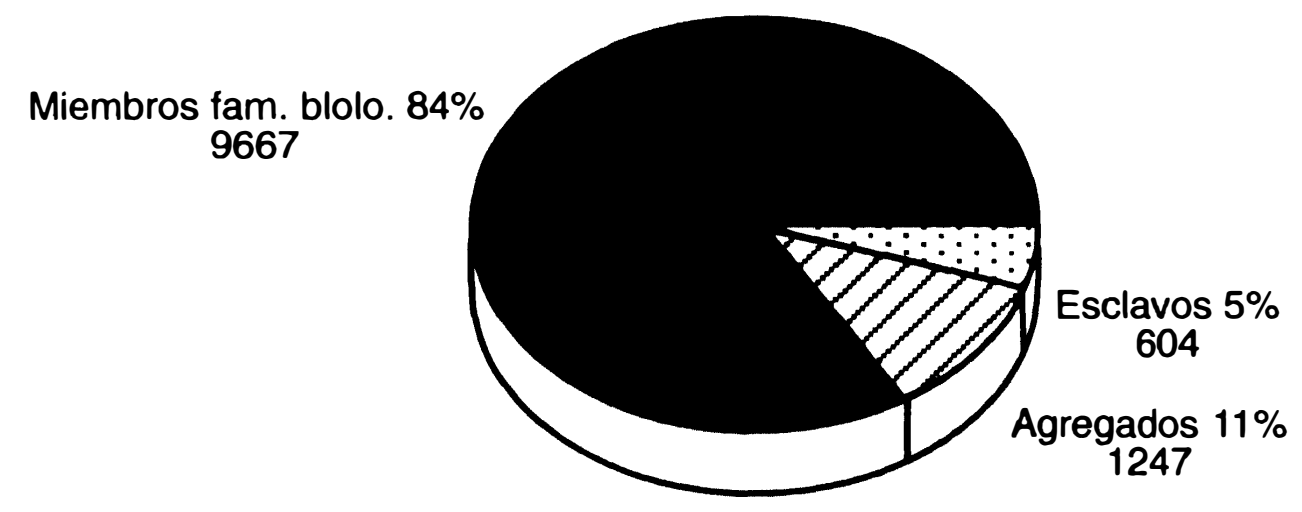

Se excluyen 631 habitantes al no haber sido registrados por unidad censal. 


\section{GRÁFICO № 2 \\ DISTRIBUCIÓN GENERAL DE LA POBLACIÓN \\ CAMPO/CIUDAD VERAGUA, 1756}

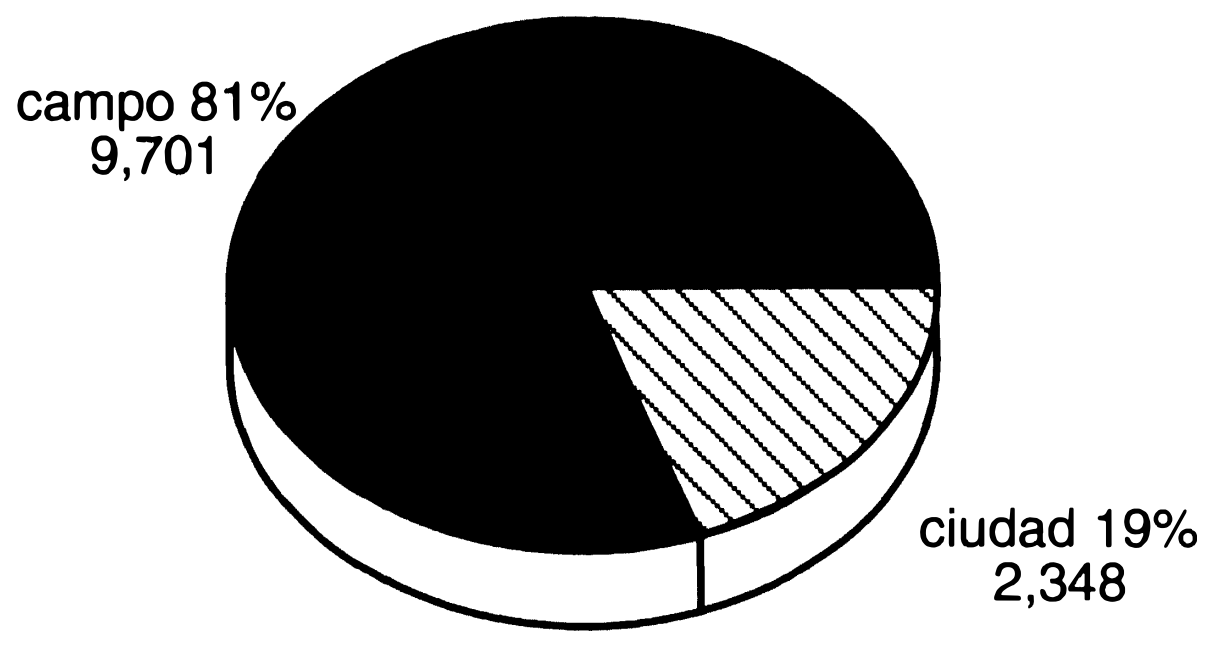




\section{GRÁFICO № 2 (Continuación)}

\section{SANTIAGO DE ALANJE}

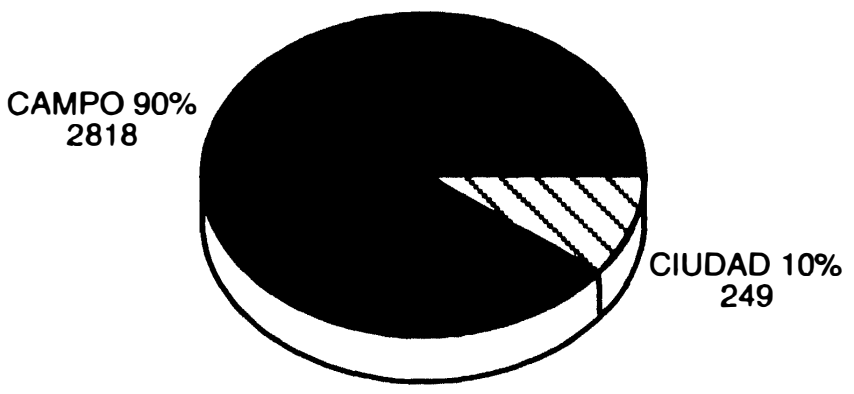

NUESTRA SEÑORA DE LOS REMEDIOS

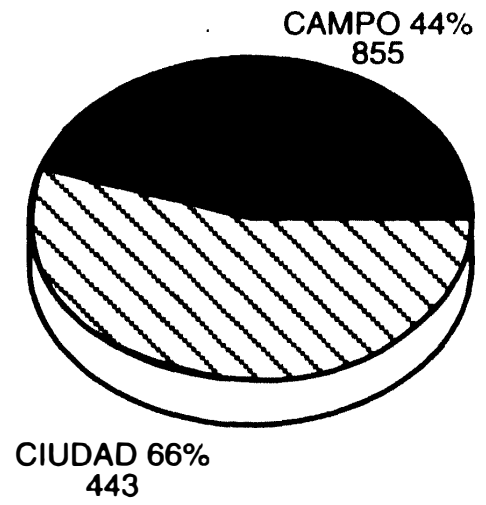

SANTIAGO DE VERAGUA

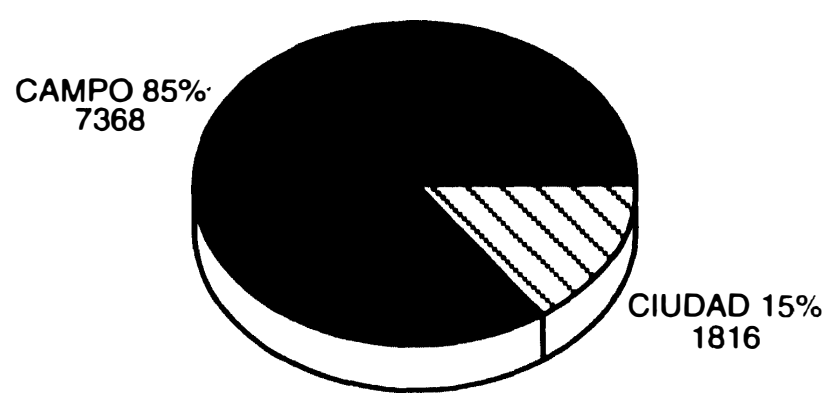




\section{GRÁFICO № 3 \\ DISTRIBUCIÓN DE LA POBLACIÓN ESCLAVA DE LA PROVINCIA DE VERAGUA. 1756}
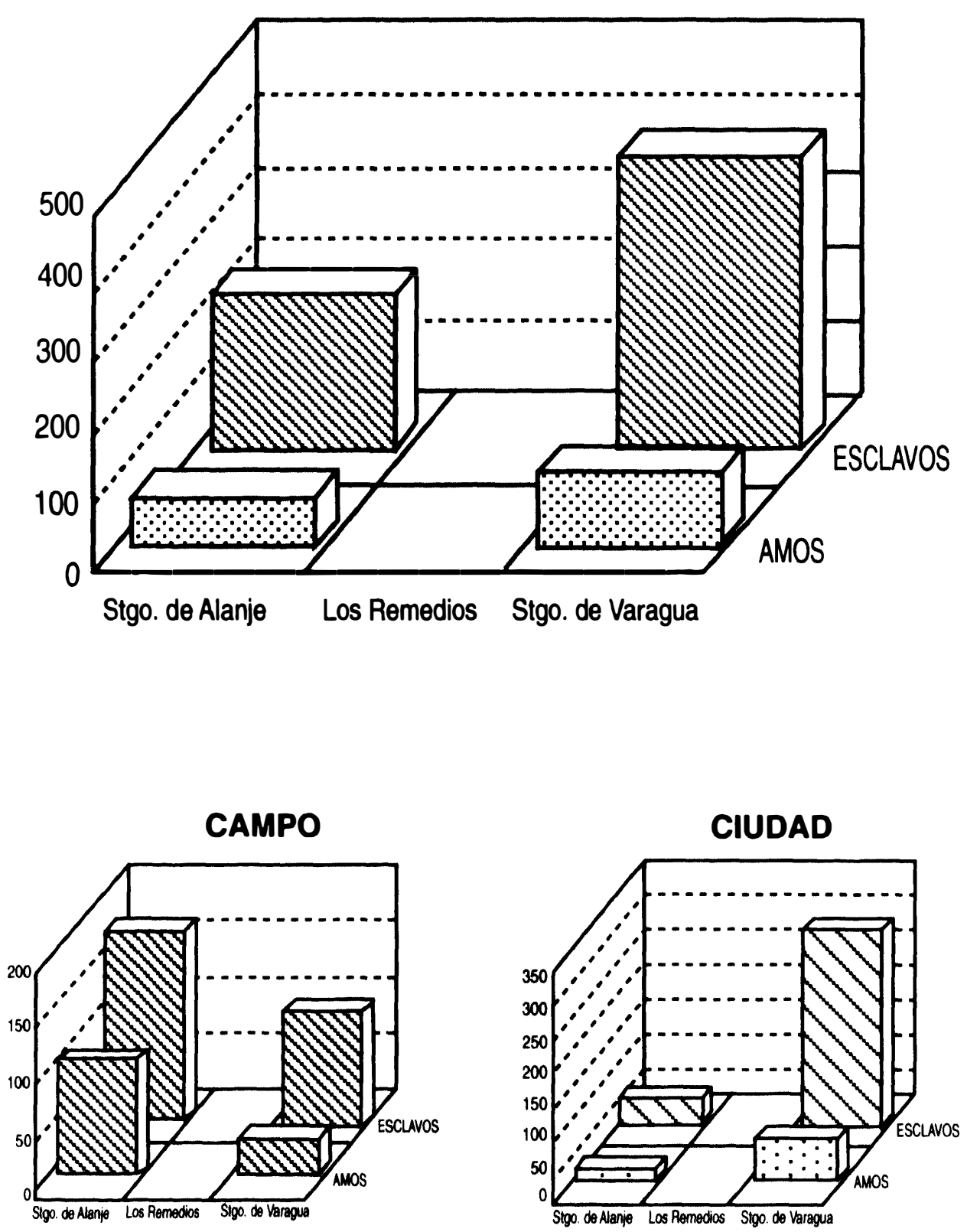


\section{Apéndice}

PADRÓN GENERAL DE TODA LA PROVINCIA DE VERAGUA EN SUS TÉRMINOS Y GOBERNACIONES QUE SE HA HECHO, POR ORDEN DE SU MAJESTAD, POR DON SANTIAGO MATÍAS GUTIÉRREZ, GOBERNADOR ACTUAL DE ELLA. AÑO DE 1756

Padrón general de los vecinos y moradores de la ciudad de Santiago de Alanje, sus casas y familias, en los términos de su jurisdicción.

Plantío (al margen).

La fábrica de dichas casas es de caña cubierta de barro y su techumbre de paja.

Justicias (al margen)

La justicia y regimiento de que se compone es de un teniente de gobernador, dos alcaldes ordinarios, un alférez real, dos alcaldes de la Hermandad, procurador general, mayordomo y un escribano del cabildo.

Iglesia, cura (al margen)

Personas Casas

La iglesia era de madera y tejas, hoy está caida. Su cura vicario es don Antonio Monfante, quien tiene esclavos tres ...............

Don Esteban Catalán, sacristán mayor, vive con su pa$004 \quad 001$ dre Don Juan Catalán, también clérigo presbítero, quien tiene dos hijos habidos en matrimonio, esclavos tres, agregados dos . . . . . . . . . . $009 \quad 001$

Don Tomás de Olivares, cura del pueblo de San Miguel de Boquerón, tiene su casa en dicha ciudad, esclavos dos y agregados ocho .........

Don Isidro de la Parra, clérigo presbítero, tiene esclavos dos y agregado uno

$011 \quad 001$

$004 \quad 001$ 
Vecinos (al margen)

Personas Casas

Don Jacinto Losada, natural de dicha ciudad, casado con doña María Josefa Aparicio, tiene esclavo uno, agregado uno

\begin{tabular}{cc}
004 & 001 \\
\hline 032 & 005
\end{tabular}

Don Matías de Candanedo, natural de los reinos de España, casado con Doña Simeona Tenorio, tiene hijos dos,

Personas Casas

(fol"f vto.) Por las sumas de la vuelta . . . . . . . . $032 \quad 005$ esclavos siete, agregado uno

$(0) 1$

El Alférez Real Don Diego de Arabal, natural de los Reinos de España, casado con Manuela de Santa María, tiene hijo uno, entenados dos, agregado uno, esclavo uno ..............

$007 \quad 001$

El Ayudante mayor don Juan de Rovira, natural del reino de Cataluña, casado con doña María Norberta de León, tiene agregado uno . . . . . . . . .

$003 \quad 001$

Don Manuel de Fuica, natural de la ciudad de Panamá, casado con Doña Estefanía de Urbaneja, tiene hijos tres, un hermano de su mujer, Don Pedro de urbaneja, agregados dos .........

$008 \quad 0() 1$

Juan de Osorio, color pardo, casado con Paula Losadas, tiene hijos ocho . . . . . . . . . . 010

001

Don Antonio García, casado con Tiburcia Osorio, tiene agragada una .............

$003 \quad 001$

María de la Concepción Angulo, color mestizo, viuda, natural de la ciudad de Panamá, tiene hija una.

$0(03($ sic $)(0) 1$

Juan Tomás Zambrano, casado con Romualda de los Reyes, tiene hijos dos

Manuel Tello, casado con Simeona Ramón, viven con el dicho tres cuñados, tiene esclavo uno, agregados tres 
Personas Casas

Don José Pérez, natural de los Reinos de España,casado con Quinteria Bejando, tiene hija una, agregados tres ..................

\begin{tabular}{ll}
007 & 001 \\
\hline 098 & 015
\end{tabular}

Don Antonio Gallardo, casado con Ma-

(fol. $\left.{ }^{\circ} 2\right)$

Personas Casas

Por las sumas de enfrente ............. 098

015

ría del Carmen Caballero, tienen hijo uno . . .

$003 \quad 001$

Don Pedro Regalado Caballero, natural de dicha ciudad, casado con Doña María del Carmen Quintero, tiene una cuñada que vive en su casa y esclavos tres y agregados dos

008

001

Silverio de Loaisa, casado con Silvestra de Ureña, tiene esclavo uno y agregado uno .........

Casimiro de Araujo, casado con Gabriela de Aguirre, tiene hijos cuatro y agregados seis . . . . . .

Pablo de Aguirre, casado con Estefanía de la Cruz, tie-

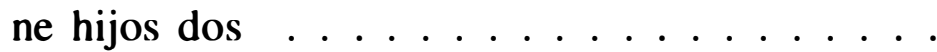

Ana María Ruiz, viuda, tiene hijos tres, esclavos cinco y agregados cuatro ...........

Simeona de Ocón, tiene hijos dos . . . . . . . . .

Dionisio Villavicencio, casado con Rafaela de Ocón .

Don Manuel Morante . . . . . . . . . . . . .

Santiago de Contreras, casado con Gregoria de Urriola, tiene hijos siete ............

Estefanía Delgado, tiene siete parientes agregados . .

Benita del Castillo, tiene hijos tres . . . . . . . . . .
Andrés de la Peña, casado con Petra Miranda, tiene hijos dos, esclavo uno y agregado uno . . . . . .

$004 \quad 001$

$012 \quad 001$

$004 \quad 001$

$013 \quad 001$

$003 \quad 001$

$002 \quad 001$

$001 \quad 001$

$009 \quad 001$

$008 \quad 001$

$004 \quad 001$

$\begin{array}{ll}006 & 001 \\ 175 & 028\end{array}$

Don Antonio Cortiza, casado con María Victorina de Flores tie- (fol." 2 vto.)

Personas Casas

Por las sumas de la vuelta . . . . . . . . . . . . 175028 
Personas Casas

nen hijos dos y esclavos dos . . . . . . . . 006

001

Manuel Rangel, receptor de la Real Hacienda, tiene esclavo uno ..................

$002 \quad 001$

Capitán Silvestre Jaramillo, tiene agregado uno . . . $002 \quad 001$

Eugenio de Castro, casado con Eufrasia Venegas . . 002001

María Venegas, tiene hijo uno . . . . . . . . . . 002001

Cristóbal Sedeño, casado con Paulina Sánchez, tiene hijas once, agregados dos ........... 015001

Doña Laureana del Castillo, tiene esclavos cinco, agregados dos . . . . . . . . . . . . .

$008 \quad 001$

Gregoria Ortega, tiene hijos cuatro .......... 005001

Juan Ignacio de los Reyes, casado con Gregoria de Medina, tiene hijos tres y agregado uno ...... $006 \quad 001$

Doña Francisca de Lara, tiene esclavos dos . . . . . $003 \quad 001$

Francisco de Escobar, casado con Luisa Fernández, tiene hijos tres, agregado uno ......... $006 \quad 001$

Francisco Javier Vélez, casado con Ignacia de Salazar, tiene hija una ............... 003001

Paula Hernández, tiene hijos dos ......... $003 \quad 001$

Manuela de Aguirre, tiene hijos dos ........ $003 \quad 001$

Don Juan Blanco, tiene agregados dos ........ $003 \quad 001$

Don Romualdo Pérez del Valle, escribano del cabildo, casado con Doña Joaquina de Santa María . . .

$002 \quad 001$

Don José Cruzado, casado con Doña Manuela de Vega,

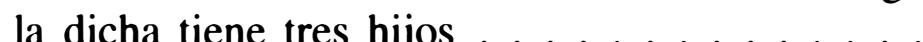

$005 \quad 001$

$251 \quad 045$

Todos los cuales se hallan en casas pobladas, en la dicha ciudad y siguen los que las tienen en los campos según sus parajes.

Personas Casas

Por las sumas de enfrente ............ 241 (sic) 045 
Don Anselmo Quintero, casado con Doña María Gutiérrez, hijos dos, esclavos diez y ocho y agregados

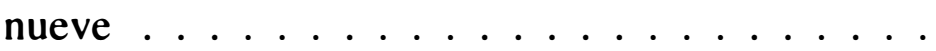

$031 \quad 001$

Doña María José Losada, tiene hijos dos, esclavos tres y agregados dos

008

001

El Sargento Mayor Don Juan Manuel Caballero, casado con Doña Gerónima Quintero, tiene hijos tres y esclavos tres ............. . .

El Capitán Don José Gamaza, casado con Doña María de la Trinidad Quintero, tiene hijos cuatro y esclavos cinco ...............

Atanasio de Ribera, casado con María de la Concepción Chavarría, tiene agregado uno, esclavos dos

Juan de Artunduaga, casado con Luisa Cabrera, tiene hijos tres ...............

Juan Enrique Sedeño, tiene hija una . . . . . . . .

Valentín de Arame, casado con Manuela Medianero, tiene hijos dos . . . . . . . . . . . . .

Juan José Gómez, casado con Clara Flores, tiene hijos

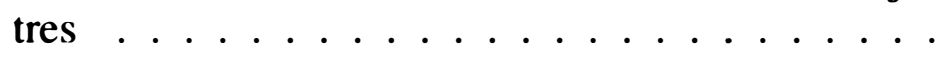

Ana Josefa Villarreal, hijos tres . . . . . . . . .

Mauricio Franco, casado con Dominga de Velasco, tiene hijos ocho, agregado uno . . . . . . . .

Raimundo Espinela, casado con María Perla, tiene hijos tres, agregado uno . . . . . . . . . . .

Mario Batista, casado con María Eufemia de Ribas, tiene hija una ..............

El Capitán Don Juan de los Ríos, casado con Doña Ana Alvarado, esclavos cịnco y agregados tres . . .

$008 \quad 001$

$011 \quad 001$

$005 \quad 001$

$005 \quad 001$

$002 \quad 001$

$004 \quad 001$

$005 \quad 001$

$004 \quad 001$

$011 \quad 001$

$006 \quad 001$

$003 \quad 001$

$010 \quad 001$

354(sic) 059

Personas Casas

(fol.” 3vto.) Por las sumas de la vuelta . . . . . . . 354059 
Personas Casas

Isabel Díaz, tiene hijos cuatro, esclavos dos y agregados dos .................

$009 \quad 001$

Don José Gallegos, vive con su madre Doña María Josefa de los Ríos, casado con María Leandra Labrador, tiene esclavos nueve y agregados dos

$014 \quad 001$

Gervasio de Olmos, casado con María de la Concepción Gutiérrez, tiene hijos cuatro, esclavos dos y agregado uno ...............

Patricio Ordóñez, casado con Magdalena Hernández, tiene hijos dos . . . . . . . . . . . .

Evaristo de Ortega, casado con Gerónima Hidalgo, tiene hijos dos . . . . . . . . . .

Casilda Ramos, tiene hijos cinco _. . . . . . . . . . . teban Catalán, casado con Polonia Vigil . . . .

Cristóbal Jarquín, tiene hijo uno . . . . . . . . . .

Ignacio Leguisamo, casado con Juliana del Castillo .

Andrés de los Ríos, casado con Gerónima Sánchez, tie-

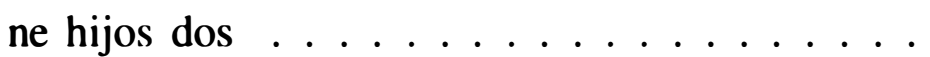

$009 \quad 001$

$004 \quad 001$

$004 \quad 001$

$006 \quad 001$

$002 \quad 001$

$002 \quad 001$

$002 \quad 001$

$004 \quad 001$

Manuel José de Salas, casado con María de la O de Escobar .................

Don Luis Durán Chacón, casado con Polonia de Almengor tiene hijos nueve . . . . . . . . .

Victoriano Galván, casado con Margarita Rivero, tiene hijos cinco, esclavos dos y agregados dos ... .

José del Carmen Veitia, casado con Francisca Galván

Don Gaspar Bruno, casado con Francisca (fol. $\left.{ }^{\circ} 4\right)$

Personas Casas

Por las sumas de enfrente $\ldots \ldots \ldots \ldots \ldots$

073

Quintero, tiene hijos dos, agregados dos . . . .

Cipriano Sánchez, casado con Estefanía de Aguilar, tie-

ne hijo uno . . . . . . . . . . . . . . .
Juan Bautista Sánchez, casado con Ambrosia Bautista, tiene hija una $\ldots \ldots \ldots \ldots \ldots \ldots$

$006 \quad 001$

$003 \quad 001$

$003 \quad 001$ 
Personas Casas

Gaspar Sánchez, casado con Josefa Arrame, tiene hijos Ocho $010 \quad 001$

Don Francisco Molina, casado con Doña Tomasa Quintero, tiene hijos cuatro, esclavos nueve y agregados tres ............... . .

Benito Popa, casado con María Patricia Domínguez, hijo uno ...............

Justa María Vázquez, tiene hijos dos . . . . . . . .

Juan Victoriano Cortés, casado con Tomasa Morena, tiene hija una ..............

Santiago Rivero, casado con Juana Isidora García . .

Francisco Ibarra, casado con María González . . . . .

Antonio Monfante, casado con Manuela Monfante, tiene hijos cinco .............

Manuel de Aparicio, tiene hijos cinco, esclavo uno y agregados catorce ............

Julián de Rojas, casado con Marta de Aparicio, tiene hijos cuatro y esclavo uno ...........

Juan de la Cruz Aparicio, casado con Juana Carreño, tiene hijos tres, esclavo una y agregados tres . .

Tomás de Guzmán, casado con María de Aguirre, tie-

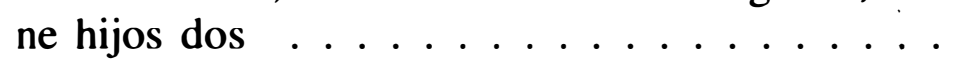

\begin{tabular}{ll}
004 & 001 \\
\hline 537 & 088
\end{tabular}

(fol. 4 vto.)

Personas Casas

Por las sumas de la vuelta . . . . . . . . . . 537088

Calixto Sedeño tiene agregados dos .......... $003 \quad 001$

Marcelo Sedeño, casado con Juana Ordóñez, tiene hi-

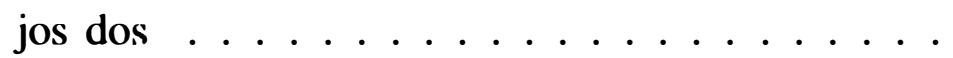

Bernabé Sánchez, casado con Rosa Pérez, tiene hijos cuatro y agregado uno ...........

Rufina Vergara, tiene hijos cinco

$003 \quad 001$

$004 \quad 001$

$007 \quad 001$

$006 \quad 001$ 
Personas Casas

Dionisio del Castillo, casado con María de la Concepción de Ureña, tiene agregados tres . . . . . . . Leonarda de Morales, tiene hijos tres . . . . . . . . Juan de Ureña, casado con Bárbara del Castillo, tiene hijos cinco . . . . . . . . . . . . .

Nicolasa de Atensio, tiene hijos seis . . . . . . Luisa de Aguilar, tiene hijos seis . . . . . . . . . Ignacio Gallardo, casado con Bernarda del Rosario, tiene hijos dos y tres más de su mujer . . . . . . Manuela Cubilla, tiene hijos tres . . . . . . . . . Manuel Pastor, casado con Bernardina Salazar, tiene agregado uno ..............

José García, casado con Lucía Aparicio, tiene agregado uno . . . . . . . . . . . . . .

Don Esteban de Avendaño, casado con Juana Paula de Utrera, tiene esclavos dos y agregados ocho . . Juan de Dios Gómez, tiene hijos dos . . . . . . . . . Juan Crisóstomo de Sosa, casado con María Ros, tiene hijos cuatro

$\begin{array}{ll}005 & 001 \\ 004 & 001\end{array}$

$007 \quad 001$

$007 \quad 001$

$007 \quad 001$

$007 \quad 001$

$004 \quad 001$

$003 \quad 001$

$003 \quad 001$

$012 \quad 001$

$003 \quad 001$

$006 \quad 001$

$625 \quad 104$

fol. $\left.{ }^{\circ} 5\right)$

Personas Casas

Por las sumas de enfrente $\ldots \ldots \ldots \ldots$

$625 \quad 104$

Alejandro Serrasín, casado con Ilaria del Castillo, tiene hijos dos . . . . . . . . . . . .

Francisco Sánchez, casado con María Victorina Flores, tiene hijos tres . . . . . . . . . . .

$004 \quad 001$

$005 \quad 001$

Nicolás Ruiz, casado con María Norberta Flores, tiene

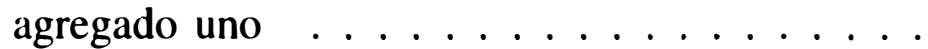

Manuel Bustavino, casado con María Carrillo, tiene hijo uno y agregados dos ............

Esteban de Ureña, tiene hijos tres y agregado uno . .

Capitán Martín Cubillas, casado con Feliciana de Santa María, tiene hijos ocho y agregados dos . . .

María de la Caridad Ricardo, tiene agregados dos . . Francisco de la Vega, tiene hijos dos y agregado uno

$003 \quad 001$

$005 \quad 001$

$005 \quad 001$

$012 \quad 001$

$003 \quad 001$

$004 \quad 001$ 
Personas Casas

Juan Manuel Blanco, casado con Teresa de Jesús, tiene hijo uno .............

Juana Sánchez, tiene hijos cinco . . . . . . . . .

Tomás de la Cruz, casado con Marcela Veristán, tiene hijo uno, agregados tres .........

Manuel Cubillas, casado con Juana Paula García, tiene hijo uno ................

Julián de Morales, casado con María Aguirre, tiene hi jos dos, esclavo uno ............

Pedro José de Ayala, casado con Manuela del Castillo

\begin{tabular}{ll}
003 & 001 \\
006 & 001 \\
006 & 001 \\
003 & 001 \\
005 & 001 \\
002 & 001 \\
\hline 691 & 118
\end{tabular}

Juan Crisóstomo de Santa María, ca- (fol.` 5 vto.)

Personas Casas

Por las sumas de la vuelta

691

118

sado con María Castillo, tiene hijos seis y agre-

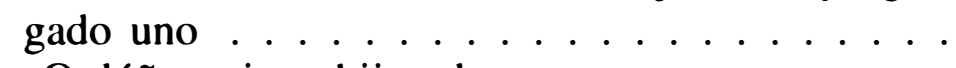

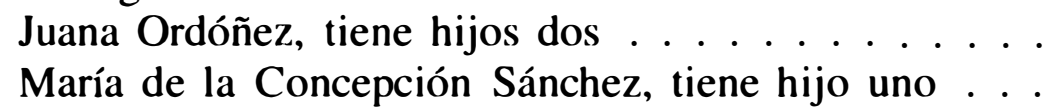

Juan del Rosario Carreño, casado con María Berrasin, tiene hijos tres . . . . . . . . . . . .

Pedro Ferrán, casado con Rufina Ortega, tiene hijos valentín de Santa María, casado con Teodora Bo-

Juan Valentín de Santa María, casado con Teodora Bo-
nilla, tiene agregados seis ......... nilla, tiene agregados seis ........

$\begin{array}{ll}009 & 001 \\ 003 & 001 \\ 002 & 001 \\ 005 & 001 \\ 006 & 001 \\ 008 & 001\end{array}$

SITIO DEL GUARUMAL Y PIEDRAS HINCADAS

Alférez Antonio de Miranda, casado con Justa Santa Ana, tiene hijos tres y agregados cuatro ....

Bernabé Chacón, casado con Simeona Chavarría, tiene hijos seis ............... . .

Felipe Romero, casado con Gregoria Morales, tiene hijo

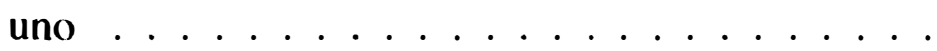

Juan de Dios Ordóñez, casado con Jacinta Zambrano, tiene hijos dos ............

$009 \quad 001$

$008 \quad 001$

$003 \quad 001$

$004 \quad 001$

Tomo 1., núm. 2, 199.3 
Personas Casas

Alonso Orocu, casado con Baltasara Chavarría, tiene

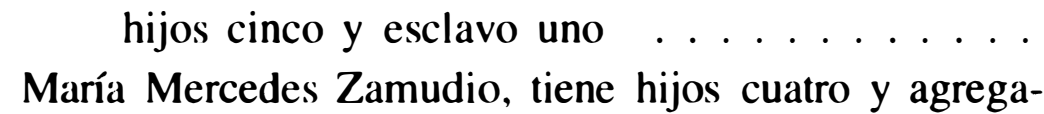
do uno

008 001

\begin{tabular}{ll}
006 & 001 \\
\hline 762 & 130
\end{tabular}

(fol."6)

Personas Casas

Por las sumas de enfrente . . . . . . . . . . . 762

Juan de Mata Becerra, casado con Ursula de Aguilar, tiene hijos seis y tres más de su mujer . . . . .

María del Rosario Aguirre, tiene hijos doce . . . . .

Gregoria Martínez, tiene hijos seis . . . . . . . . .

Simón González, casado con Petra Díaz, tiene hijos cuatro y dos más de su mujer . . . . . . . . .

Pedro Barrantes, casado con María de la Encarnación, tiene hijo uno . . . . . . . . . . . .

Juan Roberto Rivero, casado con Catalina Francisco, tiene hijos tres y otros tres más de su mujer . .

Dionisia González tiene hijos dos . . . . . . . . . .

Juan del Rosario Méndez, casado con Narcisa Morales,

tiene hijos dos . . . . . . . . . . . . . . . .
Francisco Mauro, casado con Valeria Méndez, tiene hijo uno y dos de su mujer . . . . . . . . . . . .

Nicolás de Oriamuno, casado con Juana Evangelista Carreño, tiene hijo uno y agregados cuatro . . . .

Agustín Quintero, casado con Feliciana de Aguilar .

011001

$013 \quad 001$

$007 \quad 001$

$008 \quad 001$

$003 \quad 001$

$008 \quad 001$

$003 \quad 001$

$004 \quad 001$

$005 \quad 001$

$007 \quad 001$

$002 \quad 001$

Luis Cubillas, casado con Juana de Espinosa, tiene hijo uno ....................

Francisco de Aguirre, tiene hijos tres y agregados tres

María Mercedes Salazar, tiene hijos dos . . . . . . .

Julián de Espinosa, casado con Eufemia Duarte, tiene hijo uno y otro de su mujer . . . . . . . . . . Ramón Gallo, casado con Rosa María Remón, tiene hijo uno y tres de su mujer . . . . . . . . .

\begin{tabular}{ll}
003 & 001 \\
007 & 001 \\
003 & 001 \\
004 & 001 \\
006 & 001 \\
\hline 856 & 146
\end{tabular}


Por las sumas de la vuelta . . . . . . . . . . 856

Don Melchor Barroso, casado con Andrea Cubillas, tiene hijos dos y dos de la mujer, esclavos tres y

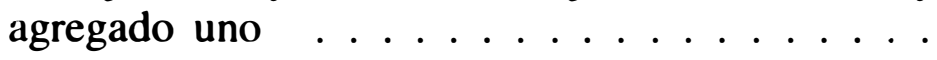

Don José Estrivis, casado con Doña María Josefa Barroso, tiene hijos seis y esclavos ocho . . . . .

Don Juan de Santa María, casado con Doña Manuela Castellón, tiene hijos tres y esclavos uno . . . .

$010 \quad 001$

$016 \quad 001$

$006 \quad 001$

Juan Gregorio Manzano, casado con Agueda de Aguirre, tiene hijos dos

$004 \quad 001$

Don Ignacio Caballero, tiene hijo uno, esclavo uno y agregados cinco ............

Doña Narcisa Barroso, viuda, tiene hijos cuatro y esclavos dos

008

001

$007 \quad 001$

Doña Marina Barroso, viuda, tiene hijo uno, esclavos

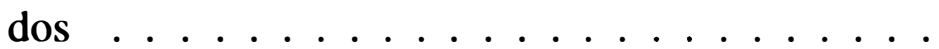

Agustina Barroso, tiene hijos tres .........

Teodoro de Arroyo, tiene hijos dos . . . . . . . .

Don Miguel Gutiérrez, tiene esclavos tres . . . . . . .

Don Ignacio Gutiérrez, casado con Doña Basilia Ruiz, tiene hijos dos, agregado uno .........

Francisco Sotelo, casado con Feliciana de Lara, tiene hijos tres .............. . .

Manuel Serseño, casado con Basilia de Lara, tiene hijo uno ...................

Tiburcio de la Cerda, casado con Clara Sedeño, tiene hijo uno, agregado uno ............

Don Matías López, casado con Polonia Sedeño, tiene hijos tres ................

Don Antonio Ruiz, casado con Doña Narcisa Chavarría, tiene agregado uno .........

\begin{tabular}{ll}
003 & 001 \\
\hline 947 & 162
\end{tabular}


Personas Casas

(fol." 7) Por las sumas de enfrente

$947 \quad 162$

Feliz Bonilla, casado con Josefa Ruiz, tiene hijos cuatro 005 (sic) 001

Don Vicente Sembreño, casado con Antonia Paniagua, tiene agregado uno ............

Manuel de Aguirre, casado con María Francisca Medianero, tiene hijo uno y otro de la mujer . . .

Benito Noriega, tiene hijos dos

Quiteria Medianero, tiene hijos dos

Valentín Nieto, casado con Feliciana de Santa María, tiene hijo uno . . . . . . . . . . . . .

Silvestre Zambrano, casado con Germana de Ulate, tiene hijo uno y otro de la mujer ........

Alejo de Santa María, casado con Salvadora Medianero, tiene hijo uno ..............

Esteban de Santa María, casado con Dominga de Velasco, tiene hijos cinco . . . . . . . . . .

Diego Medianero, casado con María de la Encarnación Ramos, tiene hijos diez y cinco más de la mujer

Patricio Vázquez, casado con Paula Ruiz, tiene hijos

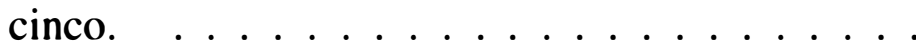

Paula Picón, tiene hijos dos . . . . . . . . . .

Ramón Solís, casado con Nicolasa Sánchez, tiene hijos

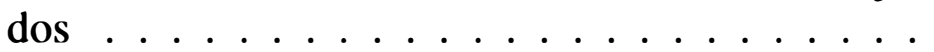

José Patricio Losada, casado con Manuela de Mendieta Pedro Sarmiento, casado con Baltasara de Mendieta .

Julián Mecenas, casado con Brígida (fol. ${ }^{77}$ vto.)

003

001

$004 \quad 001$

$003 \quad 001$

$003 \quad 001$

$003 \quad 001$

$004 \quad 001$

$003 \quad 001$

$007 \quad 001$

$017 \quad 001$

$007 \quad 001$

$003 \quad 001$

$004 \quad 001$

$002 \quad 001$

$002 \quad 001$

1.017

177

Personas Casas

Por las sumas de la vuelta . . . . . . . . . . 1.017

Barrera, tiene hijos tres . . . . . . . . . . 005

001

Manuel Sarmiento, casado con María del Carmen del Castillo, tiene hijo uno, agregados dos . . . . .

Nicolás de Saavedra, casado con Cándida Mecenas, tiene hijo uno, agregados dos . . . . . . . . .

$005 \quad 001$

$005 \quad 001$

Juan Ramírez, casado con Juana Escudero, tiene hijos tres, uno de la mujer y agregados dos . . . . 
Personas Casas

José de Lara, casado con Juana Manuela Medianiero, tiene hijo uno . . . . . . . . . . . .

Gerardo Bonilla, casado con Juana Aparicio, tiene hi-

jos dos y uno de la mujer . . . . . . . . . . .

Juan Rodríguez, casado con Isidora Osorio . . . . . .

Pedro Barría, casado con María Agustina ( )trejo, tiene hijos cinco ..............

María Arrocha, tiene hijo uno ...........

Atanasio Sánchez, tiene hijos ocho . . . . . . . .

Eugenio Chinchilla, casado con Ignacia de Santa María, tiene hijos dos . . . . . . . . . .

Marcos de la Cruz, casado con María Santiago Chinchilla, tiene hija una y dos de la mujer . . . . .

Juan Gregorio Sedeño, tiene hijos tres . . . . . . . .

Francisco de Santa María, casado con Eulalia Quintero, tiene hijo uno, esclavos dos y agregados cuatro ................. . .

María de Aparicio tiene hijos seis, esclavo uno y agregados ocho . . . . . . . . . . . . .

Manuel Medianero, casado con Clemencia Cubillas, tiene hijos cuatro, esclavos tres

\begin{tabular}{lr}
003 & 001 \\
005 & 001 \\
005 & 001 \\
002 & 001 \\
007 & 001 \\
002 & 001 \\
009 & 001 \\
004 & 001 \\
005 & 001 \\
004 & 001 \\
& \\
\hline 009 & 001 \\
016 & 001 \\
009 & 001 \\
\hline 120 & 194 \\
\hline
\end{tabular}

(fol." 8)

Personas Casas

Por las sumas de enfrente . . . . . . . . . . 1.120

194

Enrique Serrasin, casado con Dorotea Cubillas, tiene hijos dos, esclavos dos ...........

Manuela Prieto, tiene hijos cuatro, agregado uno . . .

José Méndez, casado con Manuela Casasola, tiene agrega dos tres ...............

Silvestre Osorio, casado con Juana Guerra, tiene esclavos siete .................

Juan de Aguirre, casado con Lorenza Medianero, tiene hijos tres, esclavo uno y agregado uno . . . . .

Jacinto Bonilla, tiene hijos tres . . . . . . . . .

$\begin{array}{ll}006 & 001 \\ 006 & 001 \\ 005 & 001 \\ 009 & 001 \\ 007 & 001 \\ 004 & 001\end{array}$

Tomo L., nim. 2, 1993 
Personas Casas

Jerónimo Rodríguez, casado con Paula Picardo, tiene hijos cuatro

$006 \quad 001$

Salvador Rodríguez, casado con Andrea de los Reyes, tiene hijos tres y agregado uno . . . . . . . .

Pedro Rodríguez, casado con Inés de Santa María, tiene hijos dos ..............

María Aparicio, tiene hijos ocho . . . . . . . . . .

Domingo Calzado, casado con Isidora Ontuñón, tiene

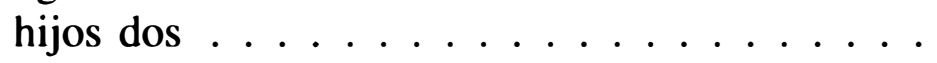

José de la Torre, casado con María del Rosario Díaz, tiene hijos dos ..............

Juan Dionisio Carrasco, casado con María del Rosario Aguirre, tiene hijo uno y agregados tres ....

Patricio Losada, casado con Juana Ocaña, tiene hijos cuatro. . . . . . . . . . . . . . . .

Luis Mateo Sánchez, casado con Juana Dorotea, tiene hijo uno. . . . . . . . . . . . .

(fol. ${ }^{\circ} 8$ vto.)

Personas Casas

Por las sumas de la vuelta $\ldots \ldots \ldots \ldots$

Andrés Badillo, casado con María del Rosario Sánchez $\quad 002 \quad 001$

María Josefa Trejo, tiene hija una . . . . . . . . . . $002 \quad 001$

María de la $\mathrm{O}$, tiene hijos tres . . . . . . . . . . $004 \quad 001$

Cayetano Sánchez, casado con Hermenegilda de Aguirre, tiene hijos tres y agregado uno .......

Blasina Medianero, tiene hijos dos y agregado uno.

\section{SITIO DEL TULLIDO Y AVACAS}

Don Jacinto Losada, tiene su casa en la ciudad y hacienda en este sitio con esclavos dos . . . . . .

Don José Losada, casado con Doña Baltasara Gutiérrez, tiene hijos cuatro, esclavo uno y agregados cinco

002 (sic) 001

$012 \quad 001$ 
Personas Casas

Don Matias de Candanedo, tiene su casa en la ciudad y hacienda en este sitio con esclavos dos y agregados tres ...............

$005 \quad 001$

Severo de la Cruz, casado con Paula Gutiérrez, tiene hijos dos y dos de la mujer . . . . . . . . $006 \quad 001$

Juan Domínguez, casado con Tomasa Moreno . . . . $\quad 002 \quad 001$

Martín de Aparicio, tiene hijo uno ........... $002 \quad 001$

Cornelio de Santa María, casado con Sebastiana Díaz, tiene hijos dos . . . . . . . . . . . . . $004 \quad 001$

Juan Rodríguez, tiene hijos cinco . . . . . . . . . 006001

Francisco de Chávez, casado con Matea Herrera, tiene hijos dos ...............

\begin{tabular}{cc}
004 & 001 \\
\hline 1.266 & 223
\end{tabular}

Rufino de Herrera, casado con Gervasia (fol." 9)

Personas Casas

Por las sumas de enfrente . . . . . . . . . . . $1.266 \quad 223$

Noriega, tienen agregado uno ........... . . $003 \quad 001$

Isabel Guevara, tiene hijos dos . . . . . . . . . . 003001

Manuel Moreno, casado con Isabel Rodríguez, tienen hijos dos y agregado uno . . . . . . . . . . .

$005 \quad 001$

Pedro Nicolás Losada, casado con Juana Gutiérrez, tiene hijos dos ..............

Alonso Coclé, casado con Clara Díaz, tiene hijos dos

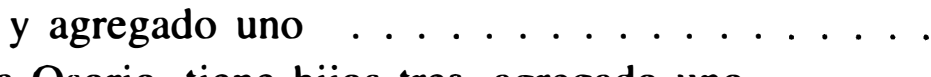

María Osorio, tiene hijos tres, agregado uno . . . . .

$004 \quad 001$

Constanza Osorio, tiene hijos dos .........

\begin{tabular}{ll}
005 & 001 \\
005 & 001 \\
003 & 001 \\
\hline 1.294 & 230
\end{tabular}

Con lo cual se cerró el padrón de todas las personas que tienen sus casas en los campos y sitios de la ciudad de Santiago de Alanje, y sigue el padrón de la Ermita de San José de David, jurisdicción de la otra ciudad, que dista de ella seis leguas. 
Padrón de la Ermita de San José de David, jurisdicción de la ciudad de Santiago de Alanje, vecinos de que se compone con distinción de los que viven en los campos.

Iglesia (al margen)

Personas Casas

La iglesia de dicha Ermita es de barro y caña y su techumbre de paja, su teniente de cura don Francisco Javier de Olivera, éste tiene una hermana nombrada Doña Juana de Chavarría, cuatro esclavos y agregados dos . . . . . . . . . . . . . $008 \quad 001$

Teniente, Don Cristóbal de Ovando, tiene su casa en
dicha Ermita por la falta de justicias que hay en ella, y asiste a los cabildos y funciones de ciudad, tiene agregados cuatro

\begin{tabular}{ll}
005 & 001 \\
\hline $013 \quad 002$
\end{tabular}

Doña Valeria Zamudio, viuda, tiene esclavos (fol." 9 vto.)

Personas Casas

Por las sumas de la vuelta . . . . . . . . . . . 013

002

cinco y agregados seis

012

001

Doña Feliciana de Arauz, viuda, tiene hijos cuatro, esclavos seis y agregados tres . . . . . . . . . .

$014 \quad 001$

Don José Cesáreo Arauz, casado con Doña María Mercedes Brenes, tiene hijos cuatro y agregados ocho

$014 \quad 001$

Don Graciliano de Arauz, casado con Doña Ignacia Contreras, tiene hijo uno y agregado uno . . . .

Silvestre Hernández, casado con Paula Atensio, tiene hijo uno y agregado uno . . . . . . . . . .

$004 \quad 001$

$004 \quad 001$

Inés Vázquez, viuda, tiene hijo uno, también viudo, nombrado Gregorio Alvarez, éste tiene hijos cuatro, agregados dos ..............

El Alférez Nicolás de Vargas, casado con Celestina Justavino, tiene hijos cinco . . . . . . . .

Miguel de Almengor, casado con Isabel de Atensio, tiene hijo uno $\ldots \ldots \ldots \ldots \ldots \ldots$ 
Personas Casas

Juan de Arizmendia, casado con Bonifacia del Castillo, tiene hijos cuatro y agregado uno . . . . . . .

Francisco Piti, casado con Juana Rodríguez, tiene hijos tres, agregado uno ..............

Doña Nicolasa Velasco, viuda, tiene hijos dos, agregado uno, esclavos dos . . . . . . . . . . .

El Alférez José de Jesús Velasco, casado con Celestina de Morales, tiene hijos seis y agregado uno

$006 \quad 001$

$006 \quad 001$

$009 \quad 001$

Don José Saavedra, casado con Doña Cipriana de Santa María, tiene hijo uno, esclavo uno y agregados

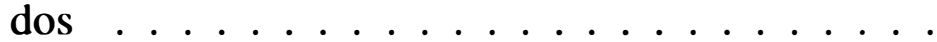

Tomás Rois, casado con María de la Encarnación Morales, tiene hijos diez y agregados tres . . . . .

(fol." 10)

Personas Casas

Por las sumas de enfrente $\ldots \ldots \ldots \ldots$

$128 \quad 016$

Domingo Martín Batista, casado con Juana de Dios del Castillo, tiene hijos seis y agregados tres . . . .

$011 \quad 001$

Capitán Don Juan de Arauz, casado con Doña Francisca Javiera González, tiene hijos tres, esclavos quince y agregados cinco . . . . . . . . . .

$025 \quad 001$

Ciprian Brenes, casado con Gerónima Montero, tiene esclavo uno y agregados cuatro ........

$007 \quad 001$

Carlos Montero, casado con Petra Morales, tiene hijos cuatro . . . . . . . . . . . . .

$006 \quad 001$

El Capitán Cándido Moreno, viudo, tiene hijos cuatro y uno de ellos casado con María Morales, tiene una hija, esclavos cinco y agregados seis . . . .

Don José de Medina, casado con Doña Bernarda de Arauz, tiene agregados dos . . . . . . . . .

Manuel de la Encarnación, casado con Juana de Aguilar

Don Tomás de los Rios, alguacil mayor del Santo Oficio, casado con Doña Gabriela Alvarez Serrano, tiene hijos cinco, esclavos quince y agregados dos .................. 
Personas Casas

Don Pio Quinto Alvarez, casado con Doña Antonia Justina de los Ríos, tiene tres sobrinos . . . . . . .

$005 \quad 001$

El Sargento José Tadeo Núñez, casado con Simeona del Castillo, tiene hijos dos . . . . . . . . .

$004 \quad 001$

Ilario de Alvarado, casado con María Josefa Contreras, tiene hijos dos y agregados dos . . . . . . . .

\begin{tabular}{ll}
006 & 001 \\
\hline 240 & 027
\end{tabular}

(fol. ${ }^{\circ} 10$ vto.)

Personas Casas

Por las sumas de la vuelta . . . . . . . . . . . 240

027

$\begin{array}{llll}\text { Francisca Contreras, viuda, tiene agregado uno } \ldots . . & 002 & 001\end{array}$

Jacinta Contreras, viuda, tiene hijos tres . . . . . . 004001

Vicenta Contreras, viuda, tiene entenados tres . . . 004001

Doña Rosa Fernández, viuda, tiene hijos cinco . . . . $\quad 006 \quad 001$

José Yáñez, casado con Benita de Vargas, tiene hijos dos, entenados cinco . . . . . . . . . .

$009 \quad 001$

Don Pedro de Aguilar, casado con Doña Florentina de Arauz, tiene hijos dos, esclavos cuatro y agrega do uno ...................

Francisco de Vargas, casado con Lorenza Moreno, tiene hijos siete y agregado uno .......... $010 \quad 001$

Isabel de Vargas, viuda, tiene agregados cuatro . . .

$005 \quad 001$

Juan García, casado con María Centeno, tiene hijo uno y agregado uno . . . . . . . . . . .

$004 \quad 001$

Juan Castellano, casado con Sebastiana Santa Ana, tiene hijo uno y agregados tres . . . . . . . . .

José Basilio Ylarrasa, casado con Ignacia del Valle, tiene hijos cuatro y agregados dos ........

Nicolás Guerra, casado con Tiburcia Contreras, tiene hijos dos ..............

Francisco Herrera, casado con Andrea de Ibarra, tiene

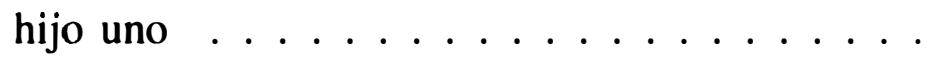

Francisca del Castillo, viuda, tiene hijo uno casado con Juana Armendía y tiene hijos dos . . . . . . . $005 \quad 001$ 
Personas Casas

Juan de Gracia, casado con Lucía Moreno, tiene hijos tres y agregado uno . . . . . . . . . . .

\begin{tabular}{cc}
006 & 001 \\
\hline 325 & 042
\end{tabular}

$\left(\right.$ fol. $\left.{ }^{\circ} 11\right)$

Personas Casas

Por las sumas de enfrente ............ 325

042

Baltasar Barria, casado con Laureana Pérez, tiene hijos

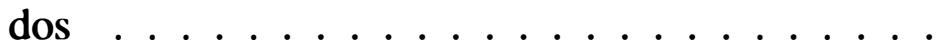

José Jiménez, casado con Juana Barría . . . . . . . .

Juan Paulino Arauz, casado con Olalla Justavino, tiene hijos cuatro ...............

Juan de la Rosa, casado con Valentina Barría, tiene hijos dos llanos.

Hasta aquí son las casas pobladas de David y siguen los ejidos y

Simeona García, tiene hijos dos . . . . . . . . . 003

Gregorio del Castillo, casado con Teodora del Cid, tie-

ne hijos cuatro . . . . . . . . . . . . . jos tres y agregado uno . . . . . . . . . . .

Raimundo de Vargas, casado con Simeona Justavino, tiene una hija de su mujer y un hermano agregado

Petra Rodríguez, viuda, tiene una nieta . . . . . . .

Juana Armues, viuda, tiene hijos tres . . . . . . . .

Martina de León, viuda, hijos tres . . . . . . . . . . .

Juan de Velasco, casado con Juana Prudencia de Espi-

nosa, tiene hijo uno . . . . . . . . . . . . . .
Florentino Moreno, casado con Bonifacia Morales, tiene hijos tres ................

Antonio Quintero, casado con Tiburcia de Atensio, tiene hijos dos y agregado uno . . . . . . . . .

$003 \quad 001$

$005 \quad 001$

$005 \quad 001$

$383 \quad 056$ 
José de Miranda, casado con Elena Quin- (fol.' 11 vto.)

Por las sumas de la vuelta . . . . . . . . .

$383 \quad 056$

tero, tiene hijos dos . . . . . . . . . . .

$004 \quad 001$

Faustino Morales, casado con María de Oroño, tiene hijos uno . . . . . . . . . . . . . .

Bernardo Sánchez vive con su madre y dos hermanos

Adrián de Atensio, casado con Tomasa de Guevara, tiene hijos dos y vive con él otro, Gregorio de Atensio, su hermano ..............

Francisco de la Cruz Espinosa, casado con Petra de Armuey tiene hijos tres y agregados dos . . . . .

Don Manuel González, casado con Isidora del Castillo, tiene hijos cuatro .............

José de Castro casado con Calixta Hernández, tiene hijos dos.

Personas Casas

$\begin{array}{ll}383 & 056 \\ 004 & 001\end{array}$

$003 \quad 001$

$004 \quad 001$

$005 \quad 001$

$007 \quad 001$

$006 \quad 001$

$004 \quad 001$

Don Salvador García, casado con Josefa de Castro, tiene hija una ...............

Juan de Santa Ana, casado con Ana Francisca, tiene hijos dos ................

María Chinchilla, viuda, tiene hija una y nietos tres y agregada una hermana con dos hijos ..... .

Pedro Pablo Carrión, casado con Joaquina de Vargas, tiene hijos cuatro ............

Valentina de Guevara, viuda, tiene agregado un cuñado ..................

Fernando Muñoz, casado con Próspera González, tiene hijos seis y de ellos una casada con Mauricio Ureña, que tiene una hija $\ldots \ldots \ldots . . .$.

$003 \quad 001$

$004 \quad 001$

$008 \quad 001$

$006 \quad 001$

$002 \quad 001$

$010 \quad 001$

$439 \quad 069$

(fol. $\left.{ }^{\circ} 12\right)$

Personas Casas

Por las sumas de enfrente . . . . . . . . . . 439

069

Valerio Justavino, casado con María Rodríguez, tiene hijos cinco y entenados dos 
Personas Casas

Julián de Miranda, casado con Manuela Morales, tiene hijos cuatro y otra más nombrada Susana de Miranda casada con Felipe Neri ......... Antonio de Aguirre, vive con su madre Tomasa de Aguirre y una hermana que tiene dos hijos ... . Pedro García, viudo, tiene hijos dos . . . . . . . . .

$008 \quad 001$

$005 \quad 001$

$003 \quad 001$

\section{SITIO DE LAS QUEBRADAS}

Pedro Pablo Suira, casado con María Ursula, tiene hijos dos, entenados cuatro y agregado uno .... . Guillermo Lezcano, casado con Juana Rodríguez, tiene hijos dos, entenados tres y agregados tres ...

$009 \quad 001$

$010 \quad 001$

José Rodríguez, casado con Paula de Aguirre, tiene hijos dos .................. . . . 004 . 001

Pedro Montero, casado con Marcela Osorio, tiene hijos

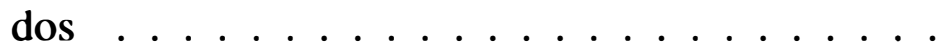

Dionisio Montero, casado con Elena Arnao, tiene hijos dos .................

Casimiro Hernández, casado con Juana Velázquez, tiene hijos siete .............

$004 \quad 001$

$004 \quad 001$

\begin{tabular}{ll}
009 & 001 \\
\hline 504 & 079
\end{tabular}

Ignacio Farragut, casado con Florencia de Osorio, tiene entenados tres y otra (fol." 12 vto.)

Personas Casas

Por las sumas de la vuelta ............. . . $504 \quad 079$

más casada con José de Artavia, que tiene hijos tres .................

Dionisio de León, casado con Mónica Contreras, tiene hijos tres y entenados tres .........

$010 \quad 001$

$008 \quad 001$ 
Personas Casas

Patricio Valdés, casado con María Montero, tiene hijo uno y entenados tres ............

Prudencia Contreras, tiene hijo uno y entenado uno

Juan del Castillo, casado con Tomasa Núñez, tiene hi-

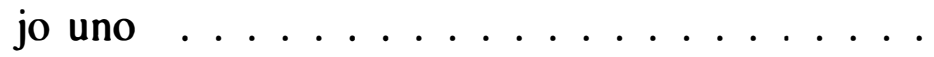

Marcelo Núñez, casado con Claudia González, tiene hi-

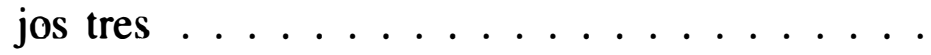

José de Torres, casado con Josefa de Quesada, tiene hijos tres .................

José Bautista, vive con su madre Clara Pérez, es casado con Juana de Ledesma, tiene agregados dos

$006 \quad 001$

$003 \quad 001$

$003 \quad 001$

$005 \quad 001$

$005 \quad 001$

$005 \quad 001$

María Bautista, tiene nietos seis y agregado a Gerónimo de Góndolas, casado con María de la O González y a Luis Gómez, casado con María de la Soledad Bautista y estos tienen dos hijos ...

Victorino Valdés, casado con Francisca González, tiene hijos dos y agregado a Bernardo de Gracia casado con Juana Licia y estos tienen dos hijos $\operatorname{dos}(\mathrm{sic}) \ldots \ldots \ldots \ldots \ldots$

\section{SITIO DE LAS LOMAS}

Juan Moreno, casado con Juana Orocu, tiene hijos cuatro

\begin{tabular}{ll}
006 & 001 \\
\hline 576 & 090
\end{tabular}

Manuel de Arias, casado con María (fol. ${ }^{\circ} 13$ )

Personas Casas

Por las sumas de enfrente $\ldots \ldots \ldots \ldots \ldots$

Moreno, tiene hijos tres y agregados dos . . . . $576 \quad 090$

Mauricio Moreno, casado con Simona Espinosa, tiene

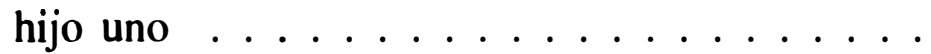

Juan José Espinosa, casado con María de Jesús González

$007 \quad 001$

$003 \quad 001$

$002 \quad 001$

Andrés Martínez, casado con Olalla Osorio . . . . .

Andrés Vele, casado con Laurencia de Santa María, tiene hijos tres ..............
$002 \quad 001$

$005 \quad 001$ 
Personas Casas

Domingo del Castillo, casado con Polonia Coello, tiene hijos dos .............

Pedro de Troya, casado con María de Gracia, tiene entenados dos y agregados dos . . . . . . . . .

José Putume, casado con Clara Vázquez, tiene hijo uno Matías del Castillo .............. Martín Nicodemus, casado con Tomasa Cándida, tiene $004 \quad 001$ hijos cuatro, agregada Casimira de Gracia, casada con Juan González

Manuel del Castillo, casado con Joaquina Justavino, tiene hijos dos y agregados cuatro . . . . . . . .

Juan José Osorio, casado con Juliana Castrejón, tiene hijos dos ................

Diego de Salazar, casado con Lucía Mendoza, tiene hijo uno y agregado uno . . . . . . . . . . . .

Bernabé López, casado con Feliciana de la Cruz, tiene hijo uno

$\begin{array}{ll}006 & 001 \\ 003 & 001 \\ 001 & 001\end{array}$

$008 \quad 001$

$004 \quad 001$

$004 \quad 001$

\begin{tabular}{ll}
003 & 001 \\
\hline 636 & 104
\end{tabular}

Sebastián Benítez, casado con Elena Ramos, tiene hijos dos y una (fol.' 13 vto.)

Personas Casas

Por las sumas de la vuelta . . . . . . . . . . $636 \quad 104$

nieta y cuatro agregados .............. 009001

\section{SITIO DEL GUAYABAL}

Silverio García, casado con María González, tiene hijos ocho y nieto uno ............. 011001

Manuela González, viuda; hijos dos ......... $003 \quad 001$

\section{SITIO DE COCHEA}

Martín Batista, casado con Juana de Dios del Castillo, tiene hijos seis, nieto uno y agregado dos ...

$011 \quad 001$ 
Personas Casas

Pedro Celestino Batista, casado con Juana García, tiene hijos dos ............... . .

$004 \quad 001$

Salvador de Lara, casado con María de la Concepción González, tiene hijos siete y agregados cinco

$014 \quad 001$

Melchor de Vargas, casado con María Cajares, tiene hijos tres ...............

Angela de Herrera, viuda, tiene hijos tres y agregados

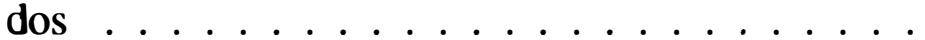

$005 \quad 001$

$006 \quad 001$

\section{SITIO DE DOLEGA}

Juan Camilo de León, casado con Juana María de Morales, tiene hijos dos . . . . . . . . . .

Domingo de León, casado con María Casilda González, tiene hijos dos ............

Atanasio González, casado con Petronila de León, tiene hijos dos y agregado uno . . . . . . . . .

Francisco Saldaña, casado con Ana Josefa Caballero, tiene hijos tres y agregados seis .......

$004 \quad 001$

$005 \quad 001$

\begin{tabular}{ll}
011 & 001 \\
\hline 723 & 116
\end{tabular}

\section{SITIO DE CHORCHA}

Don Antonio Caro, vecino de (fol. $\left.{ }^{\circ} 14\right)$

Personas Casas

Por las sumas de enfrente

$723 \quad 116$

la ciudad de Santiago de Veragua y Don Antonio Caro, su hijo, tiene el dicho Don Antonio de arriba, esclavos cuatro y agregados seis . . . . .

011001

El Alférez Raimundo de los Ríos, casado con Manuela Santa María, tiene hijos siete y agregada a su madre y a otros cuatro . . . . . . . . . . .

Juan García Pinillos, casado con Dorotea Gómez, tiene hijos cinco ..............

María de Atensio, viuda, tiene hijos tres y agregados

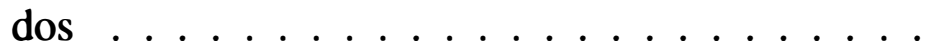


Personas Casas

Juan Picón, casado con María del Rosario Samudio, tiene hijos dos ..............

Marcelo Armendía, casado con María de Acosta, tiene

$004 \quad 001$ hijos cinco . . . . . . . . . . . . .

Lorenzo Armendía, casado con Marcelina Gómez, tiene hijos dos ..............

Juan de Santa Ana, casado con María González, tiene hijos tres y agregados dos . . . . . . . . .

Victoriano González, casado con Juana González, tiene hijos cuatro y agregado uno . . . . . . . .

Lucas Quintero, casado con Benita González, tiene hijos seis ................

Feliz Quintero, casado con Ventura González, tiene hijo uno y agregado uno ............

Carlos de Andrade, casado con María Navarro, tiene hijos cinco ..............

(fol. ${ }^{\circ} 14$ vto.)

$007 \quad 001$

$004 \quad 001$

$007 \quad 001$

$007 \quad 001$

$008 \quad 001$

$004 \quad 001$

$007 \quad 001$

$809 \quad 128$

Personas Casas

Por las sumas de la vuelta . . . . . . . . . . . . . $809 \quad 128$

Miguel de Molina, casado con Bernarda de Lara, tiene hijo uno . . . . . . . . . . . . . . . . .

$003 \quad 001$

Bernardo López, casado con Feliciana de la Cruz . .

Juan de Acosta, casado con María de la Mercedes Bravo, tiene hijo uno y agregado una .......

Petra de Chaves, viuda, tiene hijos siete ...... .

Santiago Santana, casado con Atanasia de Almengor, tiene hijos tres y nietos dos . . . . . . . .

Juan José de Castro, casado con Eusebia Flores del Canto, tiene hijos seis $\ldots \ldots \ldots \ldots$

Julián Guerrero, casado con Juana Pinillos, tiene hijos cuatro . . . . . . . . . . . . .

Juan Gil de Vargas, casado con Manuela de Espinosa, tiene hijos dos y agregados tres ........

$002 \quad 001$

$004 \quad 001$

$008 \quad 001$

$007 \quad 001$

$008 \quad 001$

$006 \quad 001$

$007 \quad 001$

Isidoro de Vargas, casado con Manuela Aparicio, tiene hijos cuatro ...............

$006 \quad 001$ 
Personas Casas

Pedro de Atensio, casado con Rosaura Valdés, tiene hijos cuatro, nieto uno y agregado uno . . . . . .

Luis Justavino, tiene esclavos tres . . . . . . . . .

Bernabé Sánchez, casado con Rosa Valdés, tiene hijos tres y agregada a su madre y a otro ......

Severino Flores, casado con Juana de Atensio, tiene agregados cuatro .............

Blas Aparicio, casado con María Rivero, tiene agregados dos ............... . .

Domingo Hurtado, casado con Sabina Justavino, tiene agregados dos ...........

(fol." 15)

\begin{tabular}{cc}
008 & 001 \\
004 & 001 \\
007 & 001 \\
006 & 001 \\
004 & 001 \\
004 & 001 \\
\hline 893 & 143 \\
\hline 893 & 143
\end{tabular}

Por las sumas de enfrente $\ldots \ldots \ldots \ldots \ldots$

Juan de Rivera, casado con Andrea María, tiene hijos dos ..................

Teodora Albaso, tiene hijos dos, agregados tres ...

Pedro Albares, casado con Leandra del Castillo, tiene hijos dos ................

Asensio de Atensio, casado con Francisca González, tiene hijos tres . . . . . . . . . . .

$004 \quad 001$

$006 \quad 001$

$004 \quad 001$

$005 \quad 001$

Dámaso de Atensio, casado con Manuela Bravo, tiene hijos seis ................

Pedro Parrilla, casado con María de Santa María, tiene hijos tres ................

Feliciano Mojica, casado con Maŕa Pinzón, tiene hijo

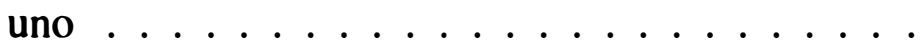

Marcela de la Cruz, viuda, tiene hijos cinco y agregados dos ...............

Pascual Serrano, casado con María Francisca, tiene hijos tres y agregado uno . . . . . . . . . . .

Eufemia Penonomense, tiene hijos dos . . . . . . .

Gregorio de Cáceres, casado con Jacoba de Armendía, tiene hijos cuatro .............

Manuel de Flores, casado con Petra González, tiene hijo

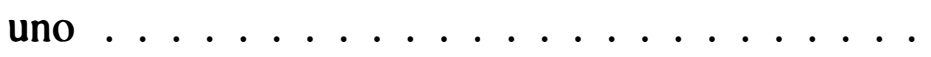

$008 \quad 001$

$005 \quad 001$

$003 \quad 001$

$008 \quad 001$

$006 \quad 001$

$003 \quad 001$

$006 \quad 001$

$003 \quad 001$ 
Personas Casas

José de Rivera, casado con Bernarda de Figueroa

002

001

Agustín de Almengor, casado con Francisca Batista, tiene hijos tres

$005 \quad 001$

Pedro Morillo, casado con Isabel de Mendieta, tiene hijos cuatro

\begin{tabular}{ll}
006 & 001 \\
\hline 967 & 158
\end{tabular}

Personas Casas

Por las sumas de la vuelta

967

158

Forasteros que se hallan al (fol ${ }^{\circ} 15$ vto.) presente viviendo en la ermita de San José de David.

Julián de Avalos . . . . . . . . . . . . . . .

001

Juan Vizcaíno ................. 001

Antonio García . . . . . . . . . . . . . . 001

Ramón Macao . . . . . . . . . . . . . . . . . 001

Don Juan José María Serrano . . . . . . . . . . 001

Francisco Arnao ................ 001

Tomás Gómez . . . . . . . . . . . . . . . 001

Santiago de los Ríos .............. 001

Pedro Camarena . . . . . . . . . . . . . . . 001

Martín Jaramillo ................. . . . . . . 001

Antonio Valderrama .............. 001

Guillermo de la Trinidad Jarquía . . . . . . . . . 001

Juan de Mata Velasco . . . . . . . . . . . . . . . . 001

Miguel Aransivia ......................... 001

Lorenzo Rodríguez . . . . . . . . . . . . . 001

Juan Pérez ..................... 001

$983 \quad 158$

Con lo cual se cerró el Padrón de la ciudad de Santiago de Alanje y Ermita de San José de David, con sus campos y vecinos que en ellos habitan y sigue en la plana de enfrente el Padrón del Pueblo de San Pablo, Doctrina de Padres Mercedarios, distante dos leguas de la otra ciudad. 
Personas de la ciudad y todos sus campos según apa-

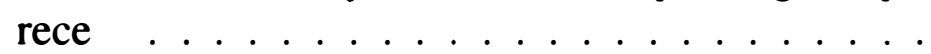

Personas de la Ermita de David y todos sus campos co-

mo parece de esta hoja . . . . . . . . . . 983

Suman

Casas de la ciudad y sus campos, según aparece: . . 230

Casas de la Ermita de David y sus campos como parece de esta hoja: . . . . . . . . . . . . . . . . 158

Suman:

(fol." 16)

Padrón del pueblo de San Pablo jurisdicción de la ciudad de Santiago de Alanje.

Dicho pueblo tiene su iglesia de barro y su techumbre de paja. Su cura, el reverendo padre fray Francisco Julián de Aguirre, del

Personas Casas

orden de Nuestra Señora de la Merced . . . . . . . .

Sacristán Mayor Don Domingo Rodríguez de Avila, presbítero ......................

Gobernador de dicho pueblo Fernando Sánchez, casado con María Ruiz

$001 \quad 001$

$001 \quad 001$

Fiscal Feliciano de Ayala, casado con Lorenza Sánchez, tiene hijos tres . . . . . . . . . . . .

Mestizo Andrés Zamudio, casado con Francisca de León, tiene hijo uno . . . . . . . . . . $003 \quad 001$

Zambo, Mariano de Vargas, casado con Dorotea Pérez, tiene hijo uno ...............

Mestizo, Salvador Morales, casado con Petra Guerrero, tiene hijo uno . . . . . . . . . . . . $003 \quad 001$

\section{Indios tributarios}

Juan de Soto, casado con Margarita Ruiz, tiene hijos dos ................. $004 \quad 001$ 
Personas Casas

Atanasio de los Santos, casado con Petra Ruiz . . . . 002001

Sebastián Pérez, casado con Bárbara Sánchez . . . . $\quad 002001$

Bernardo de los Reyes, casado con Eufemia Sarrasin, tiene hijo uno ..............

Basilio José Vizuete, casado con María Guerrero, tiene hijo uno ................

$003 \quad 001$

$003 \quad 001$

Domingo García, casado con Feliciana de Vargas, tiene hijo uno

\begin{tabular}{ll}
003 & 001 \\
\hline 035 & 013
\end{tabular}

\section{Ausentes (al margen)}

Antonio Suazo, natural del pueblo de (fol. ${ }^{\circ} 16$ vto.)

Sutiaba, en la provincia de Nicaragua, ausente, casado con Mariana Bustavino . . . . . . . . . .

Juan Antonio Murgia, indio tributario, fugitivo en mon-

$001 \quad 001$ taña, casado con María Silvestra del Canto, tiene hija una

$002 \quad 001$

\section{Indias solteras}

Simona Ruiz .................... . . $001 \quad 001$

Juana Pérez ............................ 001001

María de la Rosa Rodríguez, viuda ......... 001001

Cholos de doctrina .............. 006

Cholas mujeres de doctrina . . . . . . . . . . 008

Del pecho .................. 005

Se agrega a este padrón a Sebastián de Aguirre, ne-

gro de casta mina, esclavo del hato de San Se-

bastián, cofradía de dicho pueblo, casado con

Mnauela de los Ríos, samba agregada, tiene hijos

doctrineros tres y dél pecho uno ........

\begin{tabular}{ll}
006 & 001 \\
\hline 066 & 019
\end{tabular}

Con lo cual se concluyó el Padrón del Pueblo de San Pablo, jurisdicción de la ciudad de Santiago de Alanje; y sigue en la hoja de enfrente el Padrón del Pueblo de San Miguel de Boquerón, distante de la ciudad 
tres leguas y se pretende sacar fuera por estar metido dentro del monte y por este motivo comunicarse los indios que hay en dicho pueblo con los infieles de las montañas y hallarse la iglesia muy maltratada.

(fol. $\left.{ }^{\circ} 17\right)$

\section{PUEBLO DE BOQUERON}

Su iglesia de barro, su techumbre de paja

Personas Casas

Su cura el licenciado Don Tomás de Olivares

001

001

Gobernador español, don Juan José de los Ríos, hecho por los gobernadores de esta provincia para la reducción de indios infieles ........... $001 \quad 001$

Teniente de gobernador, Silvestre José, indio . . . . . 001001

Fiscal, Pedro Sánchez . . . . . . . . . . . . . . . . 001001

Indios tributarios . . . . . . . . . . . . . 019019

Indios del pueblo que fue de San Francisco, agregados a éste, que todavía no pagan tributo . . . . . $016 \quad 016$

Indios de dicho pueblo de San Francisco agregados a éste .................... 011011

Cholos del expresado pueblo de San Francisco, muchachos de doce a catorce años .......... 014

Mujeres de doctrina de este pueblo de Boquerón . . 033

Cholos de doctrina de Boquerón . . . . . . . . . . . 027

Cholas de doctrina ............... 008

Cholos y cholas pequeños de pecho ......... 028

Que personas y casas suman:

160

033

Con lo cual se cerró el padrón de los indios, así naturales del dicho pueblo, como los agregados a él, y sigue a la vuelta el padrón de los indios de San José de Bugaba, distante dos leguas de la expresada ciudad de Santiago de Alanje.

(fol. ${ }^{\circ} 17$ vto.)

PUEBLO DE BUGABA

Dicho pueblo tiene su iglesia de barro con su techumbre de paja. Personas Casas

Su cura el licenciado Don José Montenegro . . . . 001001 
Personas Casas

Alcalde, Tomás de Santa María . . . . . . . . . . . $001 \quad 001$ Indios tributarios . . . . . . . . . . . . . . . $008 \quad 001$

Indios agregados, dos . . . . . . . . . . . . . $002 \quad 002$

Cholos de doctrina . . . . . . . . . . . . . . . $009 \quad 001$

Indias mujeres, dieciseis f . . . . . . . . . . $016 \quad 016$

Cholas doctrineras, seis . . . . . . . . . . . $006 \quad 006$

Cholos pequeños que no asisten a doctrina . . . . . $010 \quad$.

Que personas y casas son para todos: $\quad 053 \quad 043$

Con lo cual se concluyó el Padrón del pueblo de San José de Bugaba en la provincia de Santiago de Alanje, en la cual y en sus pueblos, nóminados, hay de ganado vacuno treinta y cinco mil novecientas diez seis cabezas, que son las que se han podido ajustar, según las razones que han dado sus dueños y remitido a esta capital por el teniente de aquel partido, Don Cristóbal José de Ovando y Herrera, todo se conoce del resumen siguiente:

Personas

De la ciudad, segun aparece: . . . . . . . . . . . . 1.294

De David, según aparece: . . . . . . . . . . . . . 983

De San Pablo, como aparece: . . . . . . . . . . 66

De Boquerón en esta plana: . . . . . . . . . . . . 160

De Bugaba en esta plana: . . . . . . . . . . . 53

Suman: $\quad 2.556$

Casas

De la ciudad, según aparece: . . . . . . . . . . 230

De David aparece: . . . . . . . . . . . . . 158

De San Pablo aparece: $\quad \ldots \ldots \ldots \ldots \ldots$

De Boquerón en esta plana: . . . . . . . . . . . . 83

De Bugaba: . . . . . . . . . . . . . . . . . . 43

Que estas partidas hacen: $\quad 533$

Ganados: . . . . . . . . . . . . . . . . . . 35.916 cabezas 
(fol. $\left.{ }^{\circ} 18\right)$

Padrón general de los vecinos y moradores de la ciudad de Nuestra Señora de los Remedios (atrás Pueblo Nuevo) sujeto a la gobernación de Santiago de Veragua.

Dicha ciudad tiene su iglesia de madera y tabla, su techo cubierto de palma.

Blancos de estas Indias (al margen)

Personas Casas

Su cura, el bachiller don José del Villar.

Teniente de gobernador, Don León Celis de Saldaña, casado con Doña Tomasa Franco, tiene hijos siete

Don Juan Ambrosio Gómez, casado con Doña Josefa Saldaña

$009 \quad 001$

$002 \quad 001$

Don José Caballero, casado con Doña Ataria Hipólita Fuica, tiene hijos siete y agregada una cuñada .

$010 \quad 001$

Mestizos y mulatos (al margen)

Capitán Julián Barrera, casado con Manuela Carrera,

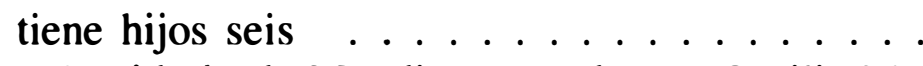

Alférez Desiderio de Mendieta, casado con Cecilia Mojica, tiene hijos cuatro . . . . . . . . . . .

Sargento Antonio de Gracia, casado con María Piedad, tiene hijos cuatro $\ldots \ldots \ldots \ldots \ldots$

Ayudante Juan Diego Lucía, casado con Bárbara de Avilés, tiene hijos dos $\ldots \ldots \ldots \ldots$

Miguel Rodríguez, tiene hijos dos . . . . . . . .

Juan Miguel de Castro tiene hijo uno . . . . . . . . .

Juan de la Ostia, casado con Ana Ruiz, tiene hijo uno

Lorenzo Mojica, casado con Petra de Soto, tiene hijo uno ..................

(fol. ${ }^{\circ} 18$ vto.)

$008 \quad 001$

$006 \quad 001$

$006 \quad 001$

$004 \quad 001$

$003 \quad 001$

$002 \quad 001$

$003 \quad 001$

$003 \quad 001$

$056 \quad 011$

Por las sumas de la vuelta $\ldots \ldots \ldots \ldots$. . . . . $056 \quad 011$ 
Personas Casas

Gregorio de Soto, tiene hijo uno . . . . . . . . . . 002

001

Jacinto Carrera, casado con María de la Concepción, tiene hijos tres .............

$005 \quad 001$

Francisco Javier Gómez, tiene agregados dos hermanos

Juan José Ulate, casado con María Espinosa, tiene hija

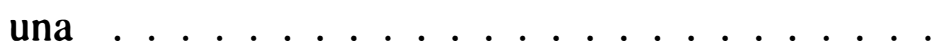

Julián de Mendieta, casado con María Gallardo, tiene hijos dos ............... . .

Manuel de Herrera, casado con María de Armuelle, tiene hijos cuatro .............

Felipe Escobar, casado con Andrea Ponce, tiene hijos cuatro ................

$003 \quad 001$

$003 \quad 001$

$004 \quad 001$

$006 \quad 001$

Esteban de Avilés.$\cdot 001$

$006 \quad 001$

001001

Antonio Valdolete, casado con Valentina Avilés ... 002001

Feliciano de la Cruz ................ 001001

Melecio de la Cruz, casado con Vicenta de Mendieta, tiene hijo uno ..............

$003 \quad 001$

Jacinto de la Ostia, casado con Manuela de Aguirre, tiene hijos siete .............

Manuel Carrera, casado con Marta Barrera, tiene hijos cuatro .................

Alberto Escudero, casado con María Fernanda de Osorio, tienen hijos cinco . . . . . . . . . .

José Carrera . . . . . . . . . . . . . . .

Cándido Carrera, casado con Hermenegilda Toribio . Juan del Rosario Carrera . . . . . . . . . . . .

$009 \quad 001$

$006 \quad 001$

$007 \quad 001$

$001 \quad 001$

$002 \quad 001$

$001 \quad 001$

$118 \quad 028$

Feliciano de la Ostia, casado con (fol. ${ }^{\circ}$ 19)

Personas Casas

Por las sumas de enfrente ............ 118

028

Juana María de Torres, tiene hijo uno . . . . . . $003 \quad 001$

Bartolomé Carrera ................ 001001

Juan José Carrera, casado con Faustina Nuñez . . . . 002001

Sebastián Barrera ................ 001001

Cayetano Mendieta, casado con Ignacia de Loyola, tiene hijo uno ................

$003 \quad 001$ 
Personas Casas

Lorenzo Mojica . . . . . . . . . . . . . . . $001 \quad 001$

Manuel Galán . . . . . . . . . . . . . . . . . $001 \quad 001$

Bernardino de Silguera, tiene hijo uno . . . . . . . $001 \quad 001$

Juan José Espinosa . . . . . . . . . . . . . . . $001 \quad 001$

Juan Crisóstomo . . . . . . . . . . . . . . . . $001 \quad 001$

Esteban Morales, casado con Josefa Romero, tiene hijos dos .................. $004 \quad 001$

Faustino de Soto ................ $001 \quad 001$

Alejandro Carrera, casado con Bernardina Espinosa . $002 \quad 001$

Lorenzo Gallardo . . . . . . . . . . . . . . . .

Francisco Cruz Espinosa, casado con Petra Armuelle, tiene hijos dos ..............

Feliciano de Espinosa, casado con Candelaria de Gracia

Silverio de la Ostia, casado con María López, tiene hijo uno . . . . . . . . . . . . . .

Manuel Pinillos $\ldots \ldots \ldots \ldots \ldots$

$001 \quad 001$

$004 \quad 001$

$002 \quad 001$

$003 \quad 001$

$001 \quad 001$

$152 \quad 046$

Salvador Herrera, casado con Valeria de los Re(fol ${ }^{\circ} 19$ vto.)

Personas Casas

Por las sumas de la vuelta . . . . . . . . . . . . $152 \quad 046$

yes, tiene hijos dos . . . . . . . . . . . $004 \quad 001$

José Macario Barrantes . . . . . . . . . . . . . . $001 \quad 001$

Juan Liberato Barrantes . . . . . . . . . . . . . . . $001 \quad 001$

Rafael Carrera, casado con Maximiliana Toribio, tiene

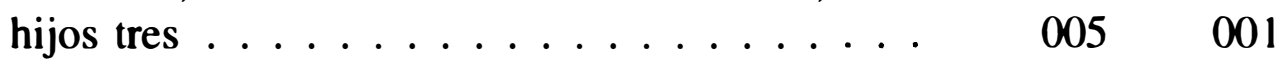

Rafael Morales ................. $001 \quad 001$

Toribio Núñez, casado con Nicolasa Gallardo . . . $002 \quad 001$

Manuel Medina, casado con Manuela Gallardo . . . $002 \quad 001$

Bartolomé Rodríguez . . . . . . . . . . . . . . $001 \quad 001$

Manuel García, casado con Micaela Quintero . . . . $002 \quad 001$

Valentín García . . . . . . . . . . . . . . . $001 \quad 001$

Tomás Valdivieso, casado con Escolástica Herrera, tiene hija una ............... $003 \quad 001$

Pablo de Trejo, casado con Juana de Avilés ..... $002 \quad 001$ 
Personas Casas

Martín de Trejo, casado con María del Pilar . . . . . 002

001

Damián González, casado con Atanasia de Ureña . .

Manuel de Arce, casado con María del Rosario de Soto, tiene hijos dos .............

$004 \quad 001$

Zambos y negros (al margen)

Capitán Feliz Flores, casado con Marcela de Aguirre, tiene hijos cuatro .............

\begin{tabular}{ll}
006 & 001 \\
\hline 193 & 063
\end{tabular}

Teniente Andrés de Carrillo, casado con (fol. ${ }^{\circ}$ 20)

Personas Casas

Por las sumas de enfrente $\ldots \ldots \ldots \ldots$

$193 \quad 063$

Valeria tiene hijos dos

$004 \quad 001$

Alférez Pedro José de la Rosa, casado con Tiburcia González . . . . . . . . . . . . . . .

$002 \quad 001$

Ayudante Salvador de Armuelle . . . . . . . . . .

Sargento José Justo, casado con María Tomasa Domínguez, tiene hijo uno ............

Cabo de escuadra Salvador de Espinosa . . . . . . . .

Juan de Rojas, casado con María de la Natividad, tiene hijos cuatro .............

$001 \quad 001$

$003 \quad 001$

$001 \quad 001$

Juan Félix Cermeño . . . . . . . . . . . .

Agustín Camarena, casado con Teodora Galano, tiene hijos tres ...............

Marcos de Acereto, casado con Manuela de Espinosa, tiene hijo uno ...............

Tomás de Aquino, casado con Bonifacia González, tiene hijos tres ...............

Salvador Serrano . . . . . . . . . . . . .

Salvador de Armuelle, casado con Josefa Cándida, tiene hijos dos ...............

001 (sic) 001

$001 \quad 001$

$005 \quad 001$

$003 \quad 001$

$005 \quad 001$

$001 \quad 001$

$004 \quad 001$

Juan de Dios de Silva, casado con Ataria de Torres, tiene hijos tres ..............

Agustín de la Rosa López, casado con Rosalía Pérez, tiene hijos tres .............

$005 \quad 001$

$005 \quad 001$ 
Personas Casas

Manuel Baltasar, casado con Victoriana Pérez, tiene hijos dos . . . . . . . . . . . . .

Feliciano González, casado con Victoria Carrera, tiene hijos tres .............

$004 \quad 001$

\begin{tabular}{ll}
005 & 001 \\
\hline 248 & 079
\end{tabular}

Antonio Gil, casado con Cándida Armue- (fol." 20 vto.)

Por las sumas de la vuelta . . . . . . . . .

Personas Casas

lle, tiene hijos cuatro . . . . . . . . . .

Juan Eugenio de Aguirre, casado con Magdalena de Santa María, tiene hijos tres . . . . . . . . . . $248 \quad 079$

$006 \quad 001$

$005 \quad 001$

Sabino González, tiene hijo uno ........... 002001

Gerardo Acereto, tiene hijo uno . . . . . . . . . . .

Juan del Rosario Armuelle, casado con Bárbara Serrano, tiene agregadas dos hermanas ...... .

Fulgencio Armuelle, casado con Juana Espinosa . . .

Eugenio de Armuelle, casado con Eufemia Carrera, tiene hijo uno ...............

$002 \quad 001$

Cayetano de Aguirre, casado con Atanasia Gaitán, tiene hijos dos ..............

Pablo de Vega . . . . . . . . . . . . . .

José de Vega Cubillas, casado con Juana de Atensio, tiene hijos seis ............... $008 \quad 001$

$\begin{array}{llll}\text { Pedro Espinosa, casado con Trinidad de la Ostia } & \ldots & 002 & 001\end{array}$

Ambrosio Pérez ................. 001001

$\begin{array}{lll}\text { Juan José Cerdeño, casado con Clemencia Hernández } & 002 & 001\end{array}$

Gregorio Saucedo, casado con Laureana García . . . $\quad 002 \quad 001$

Juan Toribio, casado con Tomasa Barrera, tiene hijos

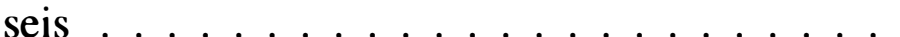

\begin{tabular}{ll}
008 & 001 \\
\hline 303 & 095
\end{tabular}

(fol. $\left.{ }^{\circ} 21\right)$

Personas Casas

Por las sumas de enfrente . . . . . . . . . . . . 303095 
Personas Casas

Esteban Toribio . . . . . . . . . . . . . . 001

001

Pedro Ruiz, casado con María de Herrera, tiene hijos

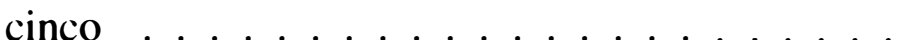
$007 \quad 001$

Luis de Zúñiga . . . . . . . . . . . . .

$001 \quad 001$

Juan Fermín de la Ostia, casado con María Crisóstoma de Aguirre, tiene hijos cinco

$007 \quad 001$

Nicolás Alejandro, tiene hija una . . . . . . . . $002 \quad 001$

Clemente de Aguirre . . . . . . . . . . . . . $001 \quad 001$

Juan de Mata de Mendoza . . . . . . . . . . . . . $001 \quad 001$

Rafael de Mendieta . . . . . . . . . . . . . . $001 \quad 001$

Lázaro Pérez, casado con María de la Ascensión, tiene hijos seis ................. $008 \quad 001$

Manuel Serrano . . . . . . . . . . . . . . . $001 \quad 001$

Agustín de los Ríos, tiene hijos cinco . . . . . . . $006 \quad 001$

Luis Rodríguez . . . . . . . . . . . . . . $001 \quad 001$

Hilario de los Reyes, casado con Juana Linares, tiene hijos tres . . . . . . . . . . . .

Marcelo Zapata, casado con Benedicta Carrera, tiene hijos cuatro ................ $006 \quad 001$

Viudas blancas(al margen)

Doña Leonor Gómez . . . . . . . . . . . . . . . $001 \quad 001$

Doña Alejandra Galán . . . . . . . . . . . . . $001 \quad 001$

Ana María de Soto . . . . . . . . . . . . . . . . $001 \quad 001$

Laureana Gamero . . . . . . . . . . . . . . . . . $001 \quad 001$

Manuela de Mendieta . . . . . . . . . . . . . . 001001

María de Santa María . . . . . . . . . . . . . $001 \quad 001$

$357 \quad 115$

María Josefa García, tiene hijas(fol.’ 21vto.)

Personas Casas

Por las sumas de la vuelta . . . . . . . . . . . $357 \quad 115$

tres ..................... . . $004 \quad 001$

Laureana de Soto, tiene hijos dos . . . . . . . $003 \quad 001$

Tomo L., nüm. 2, 1993 
Mestizas viudas (al margen)

Personas Casas

Juana María Carrera, tiene hijos dos . . . . . . . $003 \quad 001$

María Rodríguez ................ 001001

Antonia Carrera, tiene hijos cuatro ......... 005001

Cándida Carrera ................ 001001

Bibiana Espinosa ................. 001001

Juana Barrera .................. . . . . 001001

Valentina Brenes, tiene hijos seis .......... 007001

Gregoria García, tiene hijos seis . . . . . . . . . . $007 \quad 001$

Prudencia del Campo, tiene hijos cinco ....... 006001

Ana de Gracia . . . . . . . . . . . . . . . . . . . 001001

Sambas viudas (al margen)

Micaela Núñez, tiene hijos tres . . . . . . . . . . 004001

Juana Pérez, tiene hijos dos . . . . . . . . . . . 003001

Maximiliana Pérez, tiene hijo uno .......... 002001

Juana de Espinosa .................. 001001

Andrea Espinosa, tiene hijo uno ........... 002001

Tomasa González ... . . . . . . . . . . . . 001001

Petra Pérez, tiene hijos dos ........... . . $003 \quad 001$

María de Vega, tiene hijo uno . . . . . . . . . . . 002001

María de Atensio, tiene hijos dos .......... $003 \quad 001$

Justa de Armuelle .................. 001001

Olalla Sánchez .................. 001001

Atanasia de la Cruz, tiene hijo uno .......... 002001

Solteras (al margen)

Juana Prudencia, tiene hija una . . . . . . . . . 002001

Juana Marta, tiene hijos dos ............ 0 . 3001

Gerarda Rodríguez ............... 001001

Gerónima Rodríguez .............. 001001

$429 \quad 143$ 
Por las sumas de enfrente . . . . . . . . . . . . 429

María Fermina tiene hijos tres . . . . . . . . . . . . 004

Dominga Saucedo, tiene hijo uno . . . . . . . . . $002 \quad 001$

Petra Espinosa . . . . . . . . . . . . . . . . . $001 \quad 001$

Celedonia de Aguirre, tiene hijos tres . . . . . . . . $004 \quad 001$

María Susana, tiene hijos tres . . . . . . . . . . 004001

María Gallardo . . . . . . . . . . . . . . . . . $001 \quad 001$

$446 \quad 150$

Con lo cual se cerró el padrón de todas las personas habitantes de la ciudad de Nuestra Señora de los Remedios (atrás Pueblo Nuevo) y sigue el padrón del pueblo de San Feliz, jurisdicción de la dicha ciudad.

Padrón del pueblo de San Feliz, jurisdicción de la ciudad de Nuestra Señora de los Remedios (Alias Pueblo Nuevo).

Dicho pueblo tiene su iglesia que es de madera y barro cubierta de paja.

Personas Casas

Su cura doctrinero el licenciado Don Francisco Javier de Guevara, presbítero . . . . . . . . . . $001 \quad 001$

Indios de armas . . . . . . . . . . . . . . . 0290029

Indias casadas y viudas . . . . . . . . . . . . . . $035 \quad 035$

Cholos de doctrina . . . . . . . . . . . . 033

Cholas de doctrina $\ldots \ldots \ldots \ldots 21$

$\begin{array}{lll}\text { Que personas y casas suman: } & 119 \quad 065\end{array}$

$\mathrm{Y}$ aunque hay varios indios convertidos, és- (fol. 22 vto.) tos viven en el centro de las montañas y no conocen sugeción por lo que no se puede dar razón formal de ellos y sólo hay de esta clase habitantes en dicho pueblo once varones y diez hembras.

Y sigue ahora el padrón del pueblo de San Rafael, jurisdicción de la dicha ciudad de Nuestra Señora de los Remedios. 
PUEBI.O DE: SAN RAFAEL

Su iglesia es de barro y madera cubierta de paja. Personas Casas

Su cura el licenciado Don Nicolás de Guevara, presbí-

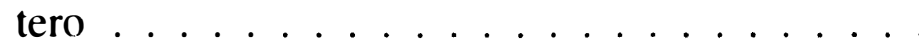

Indios de armas ................. $001 \quad 001$

Indias casadas . . . . . . . . . . . . .

Cholos de doctrina

Cholas de doctrina

030

$125 \quad 072$

$\mathrm{Y}$ aunque hay varios indios convertidos, éstos viven en las montañas y no conocen sujeción por lo que no se puede dar razón de ellos.

Y sigue en la plana de enfrente el padrón del pueblo de San Lorenzo, jurisdicción de la dicha ciudad de Nuestra Señora de los Remedios.

(fol." 23)

PUEBLO DE SAN LORENZO

Su iglesia es de madera y barro cubierta de paja.

Personas Casas

Su cura el reverendo padre fray Francisco de Paz Sol-

dán del orden de predicadores ......... 001001

Indios de armas casados .............. 010010

Mujeres de los dichos ............. 010

Indios solteros .................. 0110011

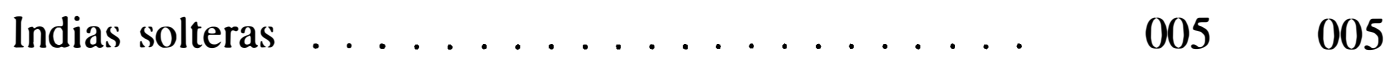

Indias viudas . . . . . . . . . . . . . . . . . . . 003003

Cholos de doctrina .............. 007

Cholas de doctrina .............. 008

Que personas y casas suman:

$055 \quad 030$

$\mathrm{Y}$ siguen los vecinos agregados que viven en este pueblo. 
Mestizos (al margen)

Personas Casas

Manuel Delgado, casado con María Bautista, tiene hijos cinco . . . . . . . . . . . . .

Domingo Bautista, casado con Cipriana Josefa Rodrí-

guez, tiene hijos cuatro . . . . . . . . . .
Pedro Gante, casado con Gregoria Bautista, tiene hijos $007 \quad 001$

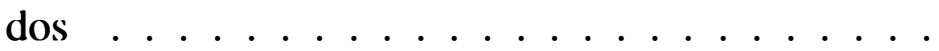

Diego Serrano, casado con Bernardina Bautista, tiene hijos dos ................

\begin{tabular}{ll}
004 & 001 \\
\hline 021 & 004
\end{tabular}

Juan Lucian, casado con fulana (fol.' 23 vto.) de tal, Personas Casas

Por las sumas de la vuelta . . . . . . . . . . 021

004 tiene hija una jos seis y agregados seis ..........

Cristóbal de la Cruz, casado con Juana de Flores, tiene hijos tres

Zambos (al margen)

Lorenzo Andrade, casado con Magdalena de Santa María, tiene hijos cuatro, agregados cuatro . . . . . José Duque, casado con Francisca López, tiene agregado uno . . . . . . . . . . . . . .

Que personas y casas suman:

$010 \quad 001$

Personas y casas de indios .............

\begin{tabular}{ll}
003 & 001 \\
\hline 056 & 009 \\
055 & 030 \\
056 & 009 \\
\hline 111 & 039
\end{tabular}

Que ambas partidas montan:

Con lo cual se concluyó el padrón del pueblo de San Lorenzo, jurisdicción de la ciudad de Nuestra Señora de los Remedios en la cual y 
en sus pueblos nombrados hay de ganado vacuno ocho mil seiscientas doce cabezas, que con las que se han podido ajustar, según las razones que han dado sus dueños y remitídose a esta capital por el teniente de aquel partido Don León Feliz de Saldaña, todo se conocerá del resumen que sigue en la plana de enfrente.

Se nota que así en (fol." 24) este pueblo como en los de San Feliz y San Rafael, aunque hay varios indios reducidos a dichos pueblos, éstos viven en el centro de las moçntañas sin ser dable el poderlos reducir a poblado con el pretexto de estar desnudos y faltos de herramientas para trabajar sus rozas, como asimismo por decir estan guardando las costas del norte y sólo se pudieran reducir a sus pueblos para que vivieran como cristianos y no como apóstatas, o con dádivas o a fuerza de rigor.

Sigue a continuación el resumen general de la ciudad de Nuestra Señora de los Remedios y los tres pueblos referidos.

Personas

De la ciudad . . . . . . . . . . . . . . . . . 446

De San Feliz . . . . . . . . . . . . . . . . 119

De San Rafael . . . . . . . . . . . . . . . . . . 125

De San Lorenzo . . . . . . . . . . . . . . 111

Que las cuatro partidas hacen: 801

Casas

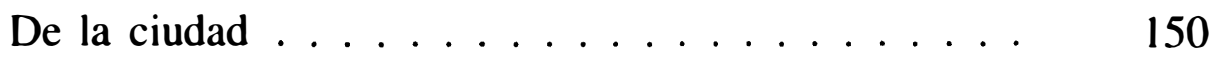

De San Feliz . . . . . . . . . . . . . . . . 065

De San Rafael . . . . . . . . . . . . . . . . 072

De San Lorenzo . . . . . . . . . . . . . . . . 039

Que estas partidas hacen: $\quad 326$

Ganados de la ciudad y tres pueblos: 8.612 cabezas

Empieza el padrón de la ciudad de Santiago y campos de su jurisdicción a la vuelta. 